University of South Florida

DIGITAL COMMONS

Digital Commons @ University of

@ UNIVERSITY OF SOUTH FLORIDA

South Florida

8-2013

\title{
Gulf of Mexico Hurricane Wave Simulations Using Swan: Bulk Formula-Based Drag Coefficient Sensitivity for Hurricane Ike
}

\author{
Yong Huang \\ University of South Florida \\ Robert H. Weisberg \\ University of South Florida, weisberg@marine.usf.edu \\ Lianyuan Zheng \\ University of South Florida \\ Marcel Zijlema \\ Delft University of Technology
}

Follow this and additional works at: https://digitalcommons.usf.edu/msc_facpub

\section{Scholar Commons Citation}

Huang, Yong; Weisberg, Robert H.; Zheng, Lianyuan; and Zijlema, Marcel, "Gulf of Mexico Hurricane Wave Simulations Using Swan: Bulk Formula-Based Drag Coefficient Sensitivity for Hurricane Ike" (2013).

Marine Science Faculty Publications. 299.

https://digitalcommons.usf.edu/msc_facpub/299

This Article is brought to you for free and open access by the College of Marine Science at Digital Commons @ University of South Florida. It has been accepted for inclusion in Marine Science Faculty Publications by an authorized administrator of Digital Commons @ University of South Florida. For more information, please contact digitalcommons@usf.edu. 


\title{
Gulf of Mexico hurricane wave simulations using SWAN : Bulk formula-based drag coefficient sensitivity for Hurricane Ike
}

\author{
Yong Huang, ${ }^{1}$ Robert H. Weisberg, ${ }^{1}$ Lianyuan Zheng, ${ }^{1}$ and Marcel Zijlema ${ }^{2}$ \\ Received 16 August 2012; revised 12 June 2013; accepted 19 June 2013; published 13 August 2013.
}

[1] The effects of wind input parameterizations on wave estimations under hurricane conditions are examined using the unstructured grid, third-generation wave model, Simulating WAves Nearshore (SWAN). Experiments using Hurricane Ike wind forcing, which impacted the Gulf of Mexico in 2008, illustrate that the default and recommended setting for the wind input parameterization tends to overestimate the maximum significant wave heights in the deep Gulf of Mexico by about $2 \mathrm{~m}$ when comparing with observations. The overestimation can be remedied either by adjusting the maximum value of the surface drag coefficient or by substituting a high wind speed formula for the default low to moderate wind speed. Because of added dissipative effects in the shallow coastal areas, the overestimations found in deep water have limited effect on the waves in the near shore shallower waters. Thus, previous wave model results using a low to moderate wind speed bulk formula may still be reliable in waters shallower than about 20-30 m even while overestimating significant wave heights in deeper waters under hurricane conditions.

Citation: Huang, Y., R. H. Weisberg, L. Zheng, and M. Zijlema (2013), Gulf of Mexico hurricane wave simulations using SWAN: Bulk formula-based drag coefficient sensitivity for Hurricane Ike, J. Geophys. Res. Oceans, 118, 3916-3938, doi:10.1002/jgrc.20283.

\section{Introduction}

[2] Hurricane Ike reached Saffir-Simpson Scale category 4 hurricane status on 4 September 2008, over the open waters of the central Atlantic. After transiting over Cuba, it moved into Gulf of Mexico (GOM) and weakened to a category 2 hurricane on 10 September 2008, before making landfall in the vicinity of Galveston, TX, with the same intensity (Figure 1). The combination of hurricane-induced storm surge and waves caused extensive damage across portions of the northwestern Gulf Coast [Berg, 2009].

[3] It is long recognized that ocean currents and waves are driven by momentum fluxes across the air-sea interface and that bulk formulae, using either a drag coefficient $C_{d}$ or a roughness length $Z_{0}$, provide the boundary layer parameterizations for models of hurricane storm surge and for the coupling of surge with waves, e.g., SLOSH (Sea, Lake, and Overland Surges from Hurricanes) by NOAA [Jelesnianski et al., 1992] for surge, and Advanced Circulation Multidimensional Hydrodynamic Model (ADCIRC) [Westerink and Luettich, 1991; Dietrich et al., 2011a; P. C. Kerr et al., U.S. IOOS Coastal \& Ocean Modeling Testbed: InterModel Evaluation of Tides, Waves, and Hurricane Surge in

${ }^{1}$ College of Marine Science, University of South Florida, St. Petersburg, Florida, USA.

${ }^{2}$ Department of Civil Engineering and Geosciences, Delft University of Technology, Delft, Netherlands.

Corresponding author: Y. Huang, College of Marine Science, University of South Florida, 140 Seventh Ave. S., St. Petersburg, FL 33701-5016, USA. (yonghuang28@gmail.com)

(C) 2013. American Geophysical Union. All Rights Reserved. 2169-9275/13/10.1002/jgrc.20283 the Gulf of Mexico, submitted to Journal of Geophysical Research: Oceans, 2013] and the Finite Volume Coastal Ocean Model (FVCOM) [e.g., Huang et al., 2010; Zheng et al., 2013] for surge and waves.

[4] Given that previous observations show that the wind drag coefficient $C_{d}$ depends not only on the local wind speed, but also on the sea state, there exists a feedback between the momentum flux and the waves [e.g., Monin and Obukhov, 1954; Charnock, 1955], and this recognition has led to two approaches for determining $C_{d}$, through observations [e.g., Large and Pond, 1981; Smith et al., 1992; Powell et al., 2003] and through theoretical considerations [e.g., Janssen, 1989; Hara and Belcher, 2004; Moon et al., 2004].

[5] Observational inferences suggest bulk formulae as piecewise functions of wind speed, although some bulk parameterizations using low to moderate wind speeds (usually less than $25 \mathrm{~m} / \mathrm{s}$ ) show only a monotonic increase of the drag coefficient with wind speed. Theoretical estimations of the drag coefficient from either two-dimensional wave spectra or vector-based wave fields also remain controversial, especially under high wind speeds. A recent empirical study by Zijlema et al. [2012] showed that the lowering of $C_{d}$ values may lead to more accurate wave simulations. This study used a curve fitted bulk formula for $C_{d}$ with values less than those of $W u$ [1982] by $10 \%-30 \%$ for wind speeds in the range of $15-32.6 \mathrm{~m} / \mathrm{s}$ and by more than $30 \%$ less for hurricane wind speeds $\geq 32.6 \mathrm{~m} / \mathrm{s}$. These uncertainties in $C_{d}$ manifest as uncertainties in wave model performances under extreme weather conditions. Three obvious questions are (1) How large are the model simulation differences using different bulk formulae, (2) which regions are most sensitive to these, and (3) what are the physics behind such sensitivity? 


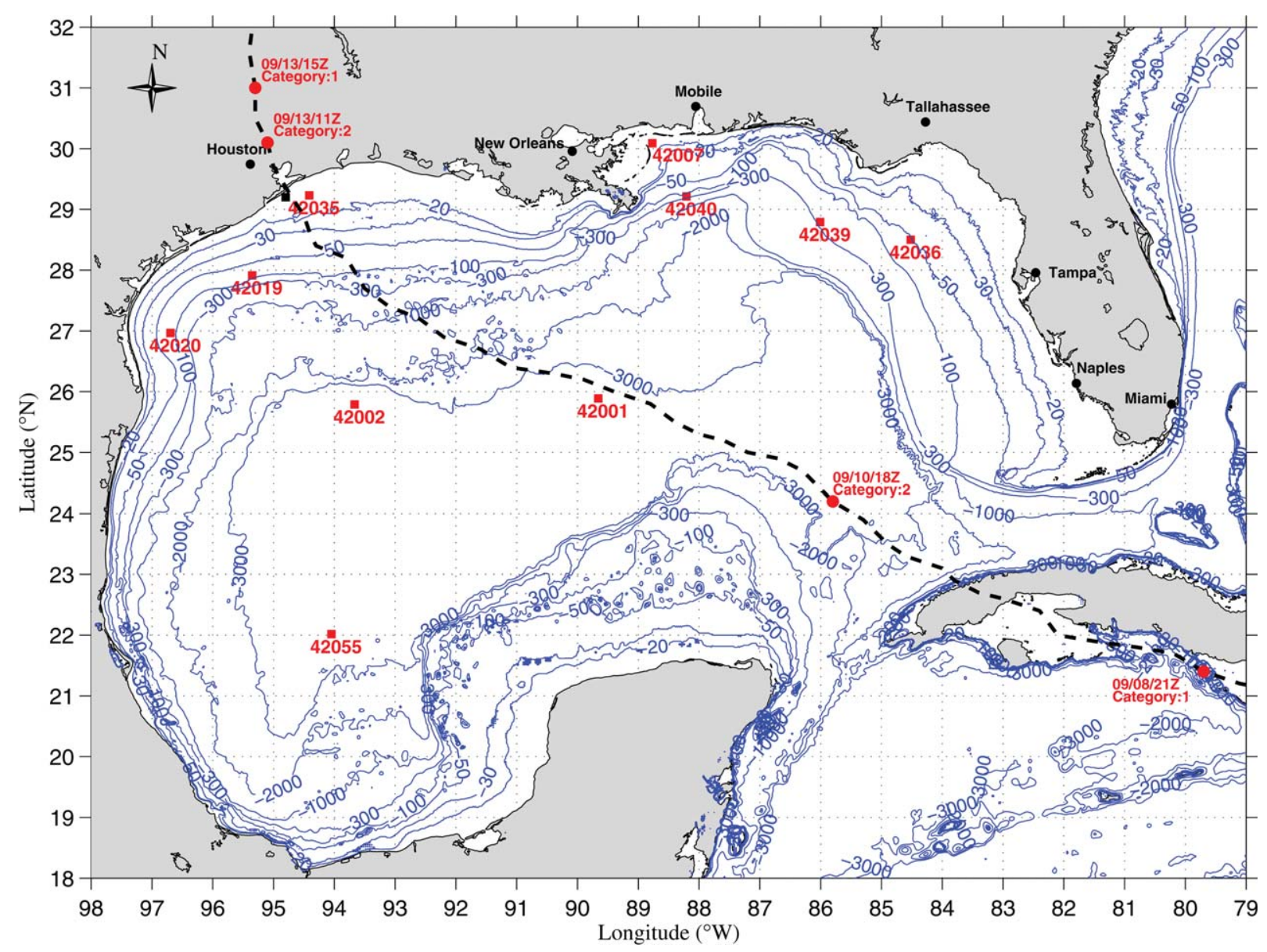

Figure 1. The bathymetry map of Gulf of Mexico with Hurricane Ike track in dashed line. Red dots on the track represent the center of hurricane. Red rectangles are positions of NDBC mooring buoys.

[6] Spectral wave models are categorized by their primary region of application, i.e., deep water (DW) models such as WAve Modelling (WAM) [WAMDI Group, 1988] and WAVEWATCH-III [Tolman, 1991; Huang et al., 2008], and Shallow Water (SW) models such as Simulating WAves Nearshore (SWAN) [Booij et al., 1999]. Whereas it is generally accepted that DW models are usually more efficient, it would be challenging for DW models to perform as good in shallow waters as SW models because SW models include additional physics representative of the shallow water environment.

[7] For hurricane wave simulations, SW models run near the coast may be nested in DW models. Despite the advantage of higher efficiency, such nonhomogeneous nested models may require different calibrations across their boundaries.

[8] The emergence of unstructured grid models removes some of this uncertainty because nesting may be avoided, affording the opportunity to evaluate the performance of an SW model over the entire computational domain. This adds a fourth question to the three enumerated earlier: (4) if a SW wave model provides reasonable results in shallow water, can it also perform similarly in deep water, and conversely?

[9] Using the forcing conditions provided by Hurricane Ike, this paper examines the sensitivity of the SW SWAN model to the drag coefficient as specified in different bulk formulae and addresses the questions raised above. Section 2 describes the model configuration and observations used for comparisons. Section 3 provides model intercomparisons and explains the differences found. Results are discussed in section 4 . Section 5 then provides a summary and a set of conclusions.

\section{Model Description and Verification Data}

\subsection{SWAN Model and Wind Input Parameterization}

[10] As a third-generation spectral wave model, SWAN is designed to obtain realistic wave estimates for any region of wind generated surface gravity waves, but especially for shallow water regions such as coastal areas, lakes, and estuaries. The physics are governed by the wave action equation [Booij et al., 1999]:

$$
\frac{\partial N}{\partial t}+\nabla_{\vec{x}} \cdot\left[\left(\vec{c}_{\mathrm{g}}+\vec{U}\right) N\right]+\frac{\partial c_{\sigma} N}{\partial \sigma}+\frac{\partial c_{\theta} N}{\partial \theta}=\frac{S_{\mathrm{tot}}}{\sigma},
$$

where $N=N(\vec{x}, t, \sigma, \theta)$ is the wave action density spectrum, as a function of the physical space and time, $\vec{x}$ and $t$, and the relative frequency and the wave direction, $\sigma$ and $\theta$. The first two terms on the left-hand side of balance equation are the local and advective rates of change of wave 
Table 1. Summary of Case Number and Associate Bulk Formulas

\begin{tabular}{ll}
\hline Case Number & \multicolumn{1}{c}{ Bulk Formula } \\
\hline CASE01 & $W u[1982], C_{d}$ cap $=$ no cap \\
CASE02 & $W u[1982], C_{d}$ cap $=2.5$ \\
CASE03 & $W u[1982], C_{d}$ cap $=2.0$ \\
CASE04 & Large and Pond $[1981]$ with a cap \\
CASE05 & Oey et al. [2006] \\
\hline
\end{tabular}

action density, where $\vec{c}_{\mathrm{g}}$ is the wave group velocity, and $\vec{U}$ is the ambient current velocity. The third term, $\frac{\partial c_{\sigma} N}{\partial \sigma}$, represents the relative frequency shifting due to variations in depth and ambient current. The fourth term, $\frac{\partial c_{c} N}{\partial \theta}$, represents the depth-induced and current-induced refraction, where $c_{\sigma}$ and $c_{\theta}$ are the propagation speeds in spectral space $\sigma$ and $\theta$. On the right-hand side, the term $S_{\text {tot }}$ includes all of the source/sink terms and represents all the physical processes that generate, dissipate, and redistribute wave energy [Komen et al., 1994].

[11] The source/sink terms are defined via the energy density $E(\sigma, \theta)$. For shallow water, $S_{\text {tot }}$ consists of six main parts:

$$
S_{\mathrm{tot}}=S_{\mathrm{in}}+S_{\mathrm{nl} 3}+S_{\mathrm{nl} 4}+S_{\mathrm{ds}, \mathrm{w}}+S_{\mathrm{ds}, \mathrm{b}}+S_{\mathrm{ds}, \mathrm{br}},
$$

where $S_{\text {in }}$ denotes the wave growth by the wind, $S_{\mathrm{nl} 3}$ and $S_{\mathrm{nl} 4}$ represent nonlinear wave energy transfers due to triad and quadruplet wave-wave interactions, respectively, and $S_{\mathrm{ds}, \mathrm{w}}, S_{\mathrm{ds}, \mathrm{b}}$, and $S_{\mathrm{ds}, \text { br }}$ are wave energy dissipations due to white-capping, bottom friction, and depth-induced wave breaking, respectively. Among those terms, the present research will focus on the contribution of wave growth by the wind input $S_{\text {in }}$. It is widely accepted that the transfer of wind energy to the waves may be conceived as the superposition of resonance [Phillips, 1957] and positive feedback [Miles, 1957] mechanisms, i.e.

$$
S_{\text {in }}(\sigma, \theta)=A+B E(\sigma, \theta),
$$

for which $A$ represents a linear growth part and $B E(\sigma, \theta)$ represents an exponential growth part. The former contributes to the initial stages of wave growth, while the latter, representing a positive feedback proportional to the wave energy itself, provides for exponential growth.

[12] The default algorithm for exponential growth in SWAN is based on the observations of Snyder et al. [1981], rescaled and expressed as a function of friction velocity $U_{*}$ by Komen et al. [1984]:

$$
B=\max \left[0,0.25 \frac{\rho_{\mathrm{a}}}{\rho_{\mathrm{w}}}\left(28 \frac{U_{*}}{c_{\mathrm{ph}}} \cos \left(\theta-\theta_{\mathrm{w}}\right)-1\right)\right] \sigma,
$$

where $\theta$ is the direction space, $\sigma$ is the frequency space, $\theta_{\mathrm{w}}$ is the wind direction, $c_{\mathrm{ph}}$ is the phase speed and $\rho_{\mathrm{a}}$ and $\rho_{\mathrm{w}}$ are the density of air and water, respectively. Thus, $U_{*}$ is the key exponential growth parameter. SWAN adopts the bulk function from $W u$ [1982] to calculate $U_{*}$ from the wind speed at $10 \mathrm{~m}$ elevation $\left(U_{10}\right)$ :

$$
\begin{gathered}
U_{*}^{2}=C_{d} \times U_{10}^{2}, \\
C_{d} \times 10^{3}= \begin{cases}1.2875 & U_{10}<7.5 \mathrm{~m} / \mathrm{s} \\
\left(0.8+0.065 \times U_{10}\right) & U_{10} \geq 7.5 \mathrm{~m} / \mathrm{s}\end{cases}
\end{gathered}
$$

[13] Given that this bulk formula has $C_{d}$ increasing linearly with wind speed and a default setting without upper limit, or cap, is it appropriate under hurricane conditions?

\subsection{Bulk Formula-Based $\boldsymbol{C}_{\boldsymbol{d}}$}

[14] Here the bulk formula [Wu, 1982] adopted in SWAN is treated as a baseline for comparisons with other alternatives. In its original form, this bulk formula does not cap the value of $C_{d}$ at high wind speed $\left(U_{10} \geq 7.5 \mathrm{~m} / \mathrm{s}\right)$, whereas the SWAN manual [SWAN Group, 2011] recommends an upper limit of $C_{d}=2.5$. To investigate the model sensitivity for different $C_{d}$ cap values, three selected values are chosen: "no cap," 2.5 and 2.0. The no cap is the default setting in SWAN. The value " 2.5 " is recommended in the SWAN manual [SWAN Group, 2011]. The value "2.0" is subjectively selected to fit the Hurricane Ike case based on numerical experiments.

[15] Consideration is also given to two other bulk formulae, one by Large and Pond [1981] with a cap added at high wind speed $\left(U_{10}>25 \mathrm{~m} / \mathrm{s}\right)$, i.e., the third line in (7) as adopted by Weisberg and Zheng [2008]:

$$
C_{d} \times 10^{3}= \begin{cases}1.2 & U_{10}<11 \mathrm{~m} / \mathrm{s} \\ 0.49+0.065 \times U_{10} & 11 \mathrm{~m} / \mathrm{s} \leq U_{10} \leq 25 \mathrm{~m} / \mathrm{s} \\ 0.49+0.065 \times 25 & U_{10}>25 \mathrm{~m} / \mathrm{s}\end{cases}
$$

the other an extrapolation from Large and Pond [1981] at high wind speed $\left(U_{10} \geq 19 \mathrm{~m} / \mathrm{s}\right)$, i.e., the third line in (8) as applied by Oey et al. [2006] and Wang and Oey [2008] and as motivated by the hurricane sea state data of Powell et al. [2003]:

$$
C_{d} \times 10^{3}=\left\{\begin{array}{ll}
1.2 & U_{10} \leq 11 \mathrm{~m} / \mathrm{s} \\
0.49+0.065 \times U_{10} & 11 \mathrm{~m} / \mathrm{s}<U_{10} \leq 19 \mathrm{~m} / \mathrm{s} \\
1.364+0.0234 \times U_{10}-0.00023158 \times U_{10}^{2} & 19 \mathrm{~m} / \mathrm{s}<U_{10} \leq 100 \mathrm{~m} / \mathrm{s}
\end{array} .\right.
$$

[16] Table 1 summarizes all these selected bulk formulations, and the relationships between $C_{d}$ and $U_{*}$ with $U_{10}$ are shown in Figure 2. The sensitivity of the positive feed- back mechanism to the drag coefficient is developed in following sections. 

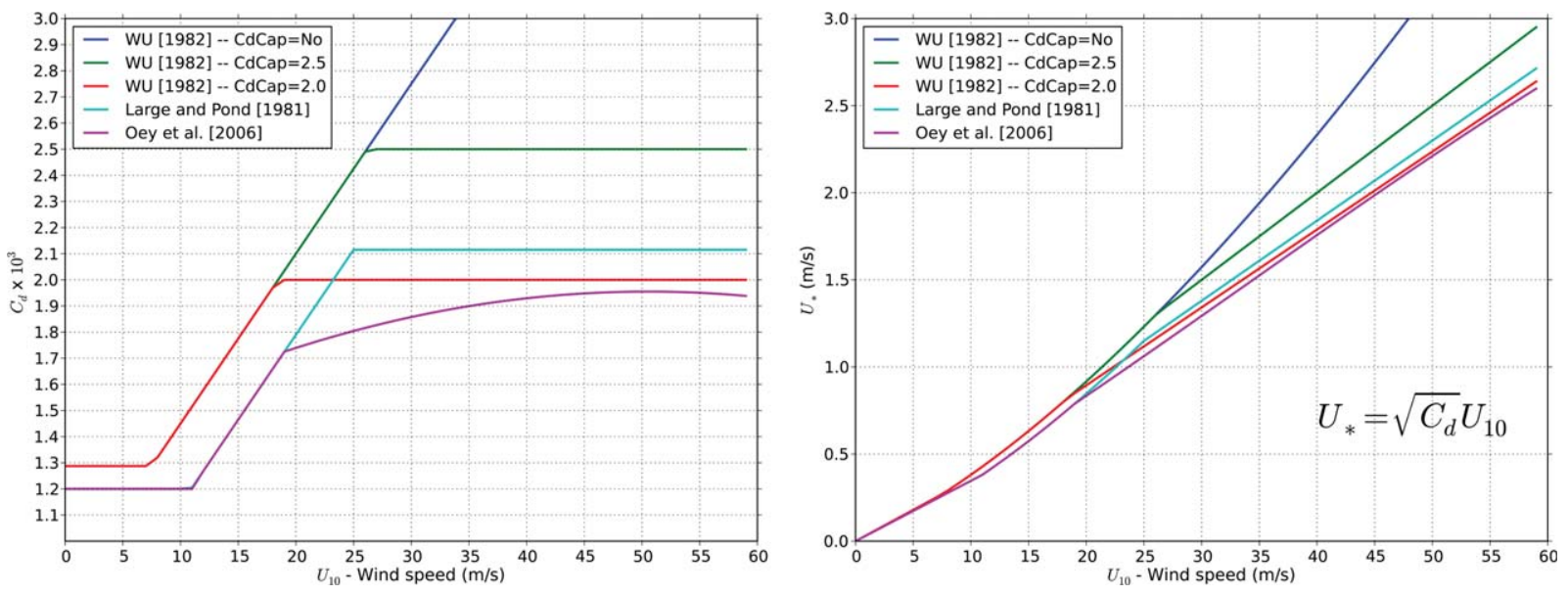

Figure 2. Profile of (left) $U_{10}-C_{d}$ and (right) $U_{10}-U_{*}$ relationships based on different bulk formulae.

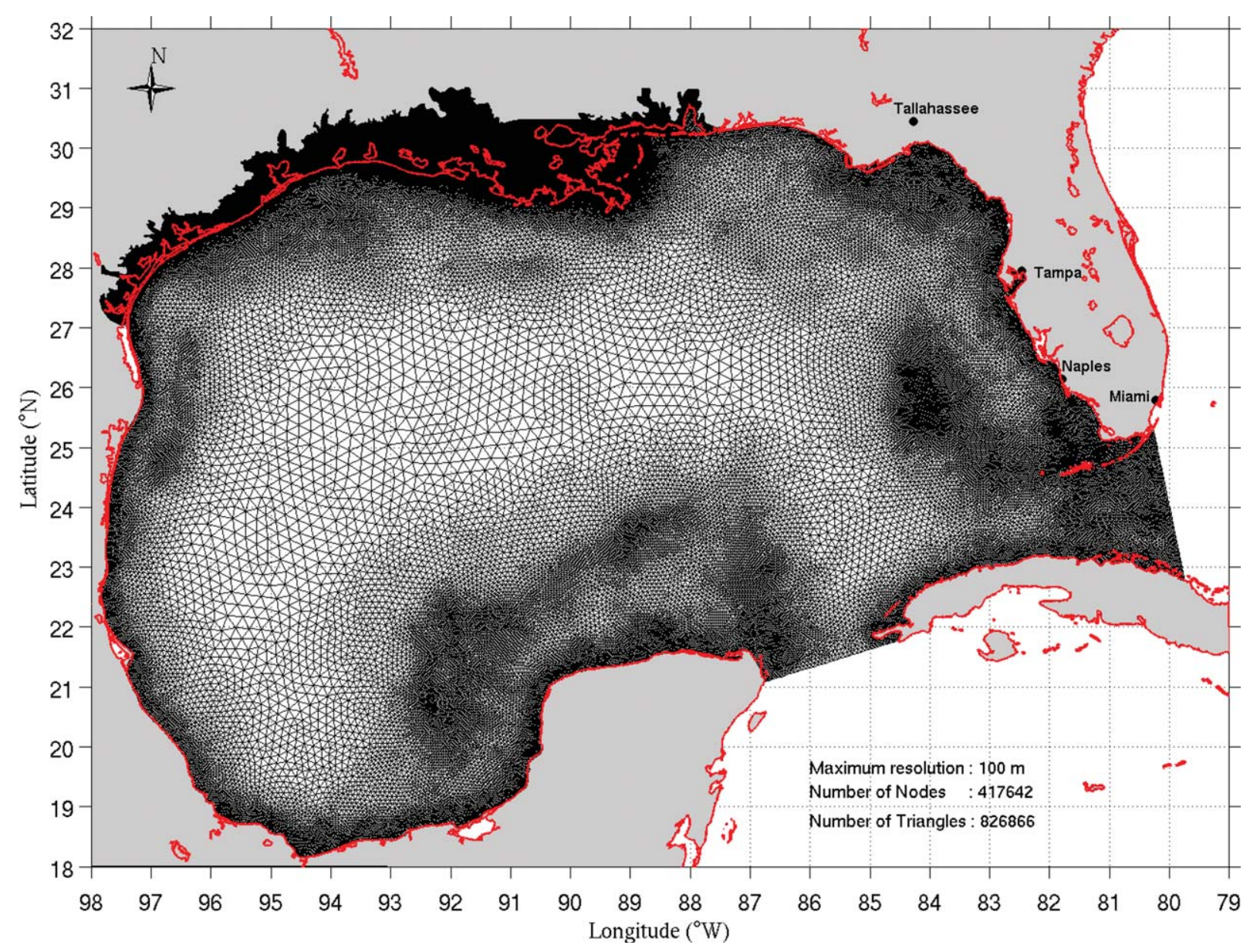

Figure 3. The unstructured triangular grids used in this study.

\subsection{Model Implementation}

[17] The SWAN model application reported on here was performed as a component of a Gulf of Mexico coastal inundation project contained within the Southeastern Universities Research Association led Integrated Ocean Observing System (SURA-IOOS) Super-regional Model
Testbed. Our application used the unstructured triangular mesh grid version of SWAN [Zijlema, 2010]. This was fit to the SL + TX_GoM_UL01-LR (ULLR) Testbed grid provided by Kerr et al. (submitted manuscript, 2013). The Testbed grid had 826,866 triangular elements with 417,642 nodes, and its domain included the entire Gulf of Mexico 
A
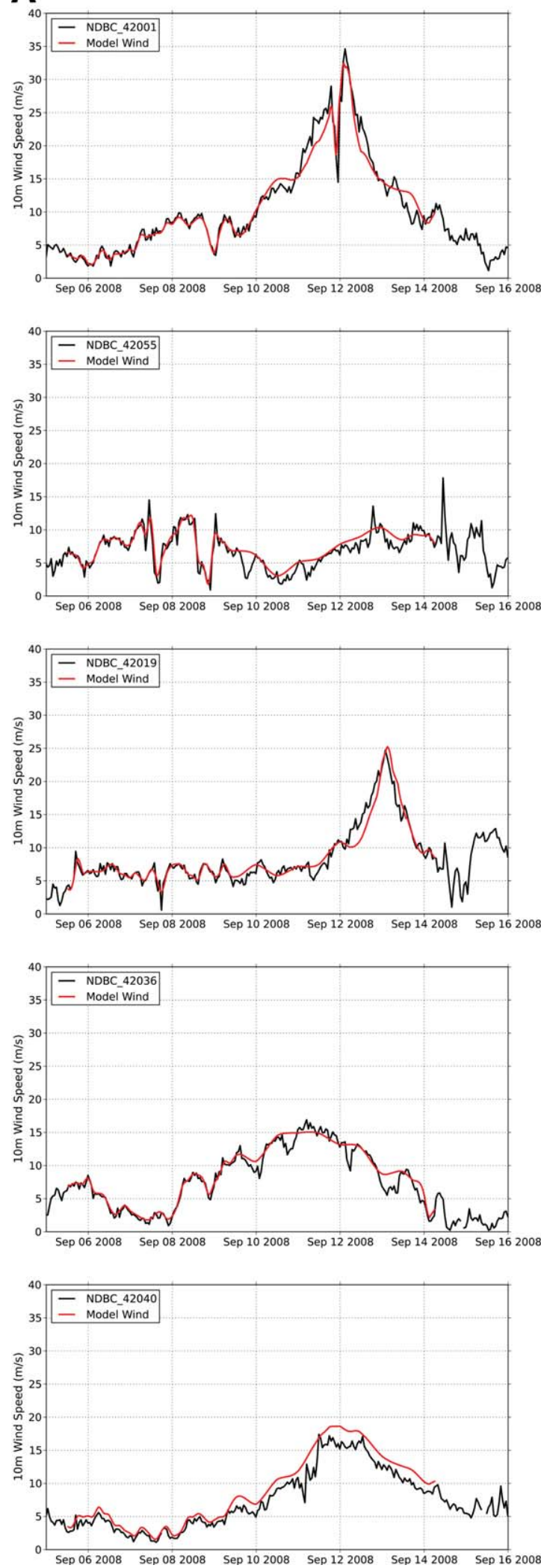
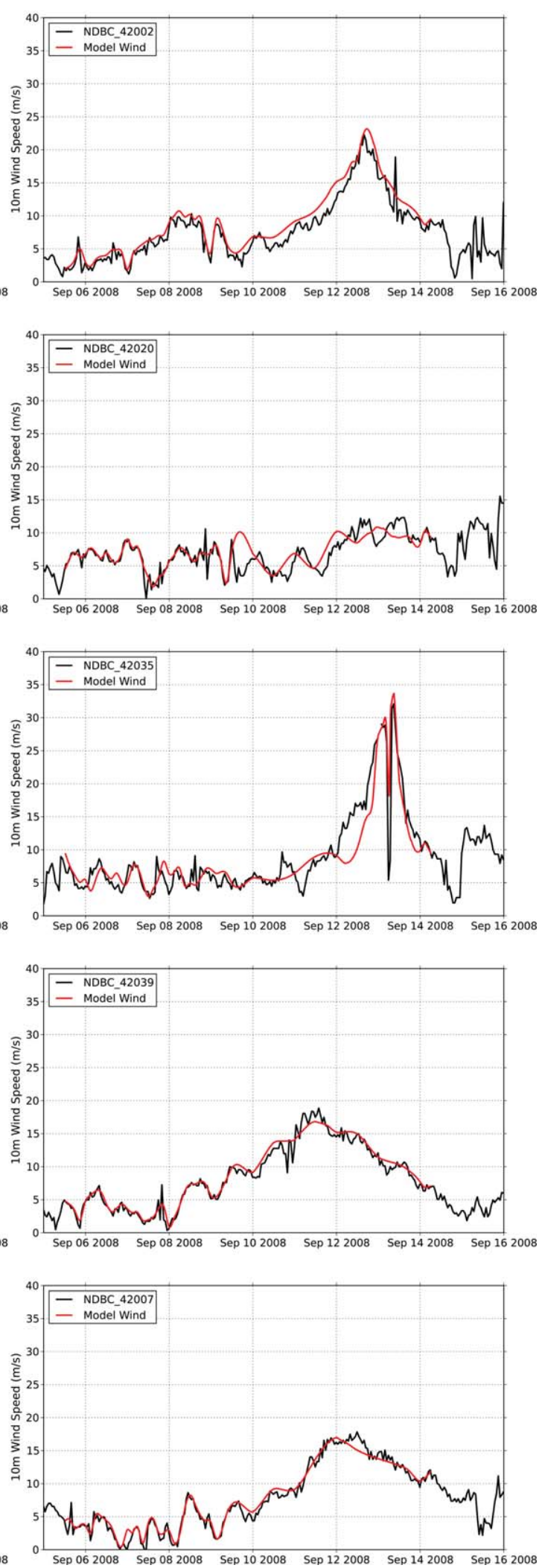

Figure 4. Time series of $10 \mathrm{~m}$ above sea surface wind (a) speed and (b) direction of Hurricane Ike comparison against NDBC mooring buoys observed data. (c) The maximum $10 \mathrm{~m}$ above sea surface model wind speed of Hurricane Ike. 
HUANG ET AL.: DRAG COEFFICIENT FOR HURRICANE WAVE

B
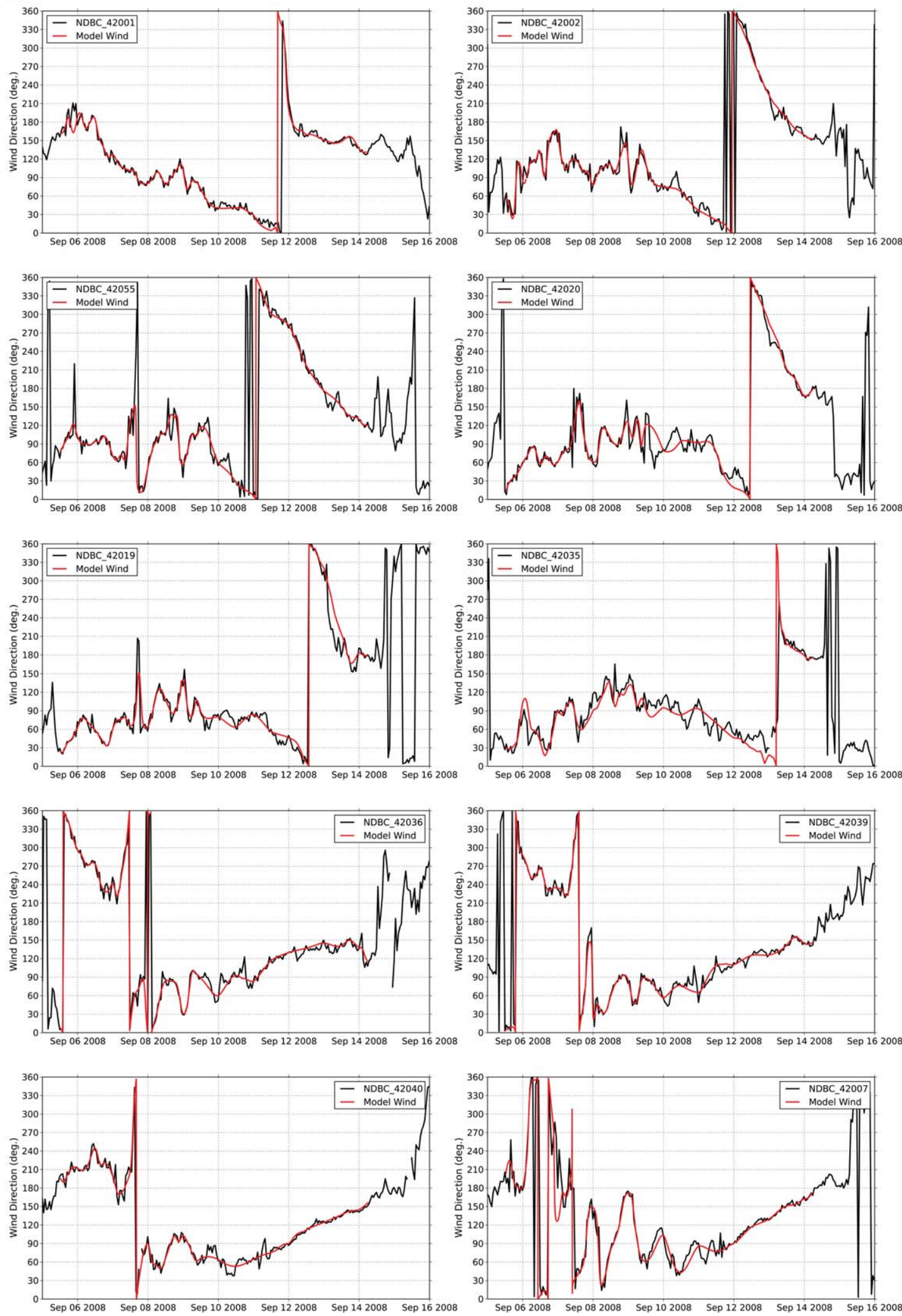

Figure 4. (continued) 


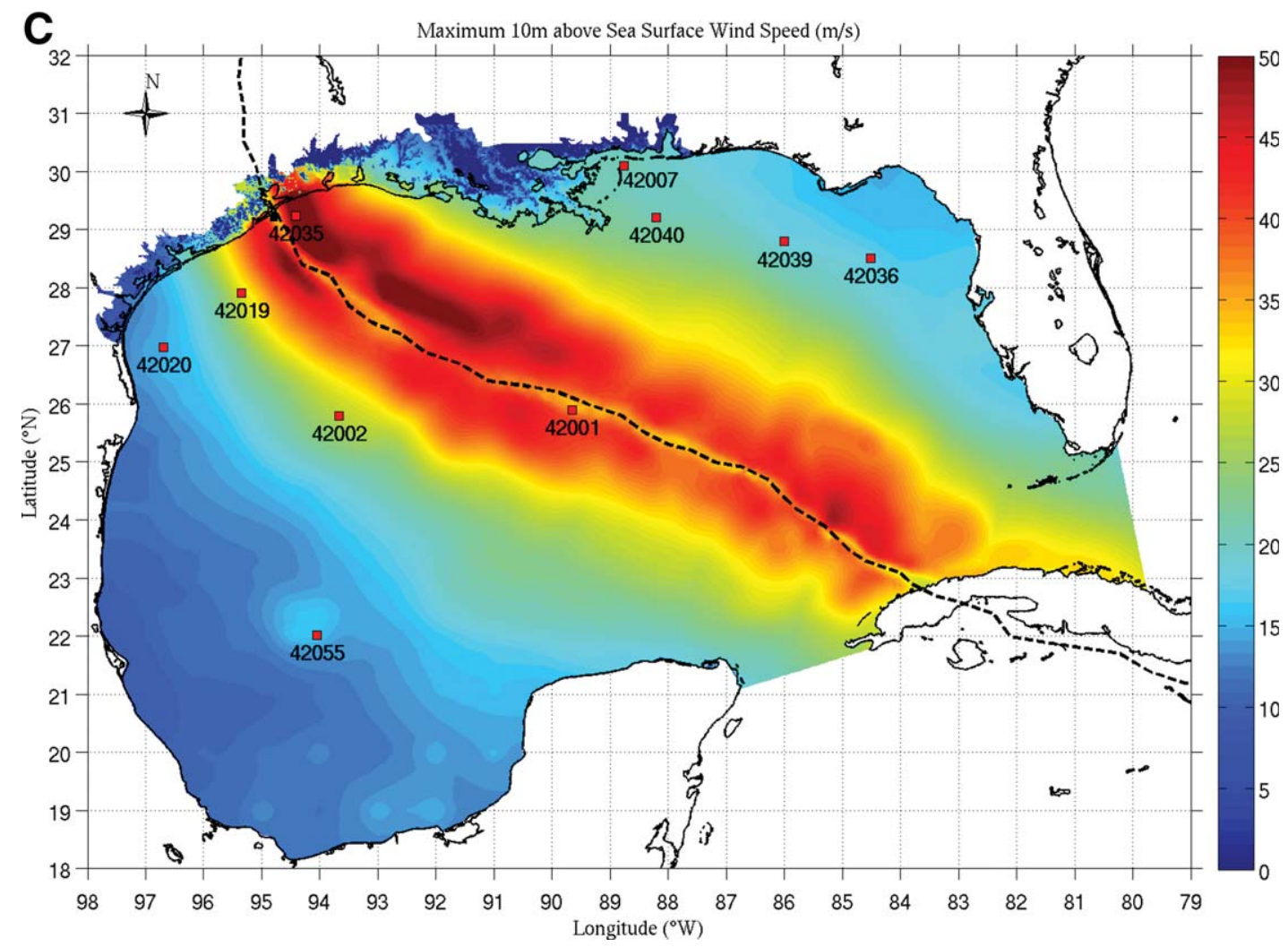

Figure 4. (continued)

with two open ocean boundaries at the Florida and Yucatan Straits (Figure 3). Wave energy was solely generated within the domain, i.e., wave energy propagated out, but could not propagate in through the open boundaries. The grid was designed for coastal inundation, storm surge, and wave modeling. The resolution varied from $8-30 \mathrm{~km}$ in the deep Gulf of Mexico to $2-8 \mathrm{~km}$ along the continental shelf to 100 to $2000 \mathrm{~m}$ near shore, in rivers, and on the overland areas of the Texas and Louisiana coasts. Particular attention was given to resolving features of the coast near Galveston, TX, where Hurricane Ike made landfall.

[18] For simplicity in studying the waves over the domain as a whole, the effects of ambient currents [Whitham, 1974] and surge variations near shore [Huang et al., 2010] are switched off. Only the data-assimilated wind field at the 10 $\mathrm{m}$ reference level acts as the driving agent. The model wind field was derived from NOAA's Hurricane Research Division Wind Analysis H*WIND Product [Powell and Houston, 1996; Powell et al., 1998, 2010] and was preprocessed through ADCIRC [Hope et al., manuscript in preparation, 2013]. Time series comparisons of the analyzed wind speeds and directions with those observed at various National Data Buoy Center (NDBC) moorings (and scaled to the $10 \mathrm{~m}$ reference level) are plotted in Figures $4 \mathrm{a}$ and $4 \mathrm{~b}$, respectively. Relative to the storm track, Figure $4 \mathrm{c}$ shows the maximum Hurricane Ike wind speeds (at the $10 \mathrm{~m}$ level).

[19] For our SURA Testbed numerical experimental purposes, the SWAN time step interval is $5 \mathrm{~min}(300 \mathrm{~s})$. The spectrum resolution settings follow the values adopted by the National Oceanic and Atmospheric Administration
(NOAA) operational WAVEWATCH-III model [H. Tolman, personal communication]. The frequency space ranges from 0.035 to $0.9635 \mathrm{~Hz}$, discretized into 50 bins on a logarithmic scale $(\Delta \sigma / \sigma=0.07)$. We note that our own model sensitivity experimentation (see Appendix) demonstrated that the use of 0.07 versus the default value of 0.1 resulted in only minor $(0.01-0.03 \mathrm{~m})$ differences at the $10 \mathrm{NDBC}$ buoy locations that were used for comparisons of model simulations with observations. The direction space is equally discretized into 36 sectors, $10^{\circ}$ for each sector. The present simulations use the modified white-capping expression of Rogers et al. [2003]. The quadruplet wavewave interactions are computed with the Discrete Interaction Approximation (DIA), as proposed by Hasselmann et al. [1985]. For the shallow water physics, the default shallow water scaling for DIA is active [Booij et al., 1999], depth-induced breaking is computed with a spectral version of the model due to Battjes and Janssen [1978] with the breaking index $\gamma=0.73$, bottom friction is based on the empirical JONSWAP formulation [Hasselmann et al., 1973] with friction coefficient $C_{\mathrm{b}}=0.019 \mathrm{~m}^{2} \mathrm{~s}^{-3}$ (as used in the NOAA operational WAVEWATCH-III model for the Gulf of Mexico). As with our sensitivity experiments on relative frequency resolution, when comparing the model sensitivity to bottom drag coefficient (data not shown), it was found that the SWAN default values of 0.038 or 0.067 resulted in the underestimation of significant wave height in shallow water; hence our adoption of 0.019 for this parameter value.

[20] Regarding refraction, numerical experiments demonstrate that the grid resolution near the shelf break is not 


\section{A}
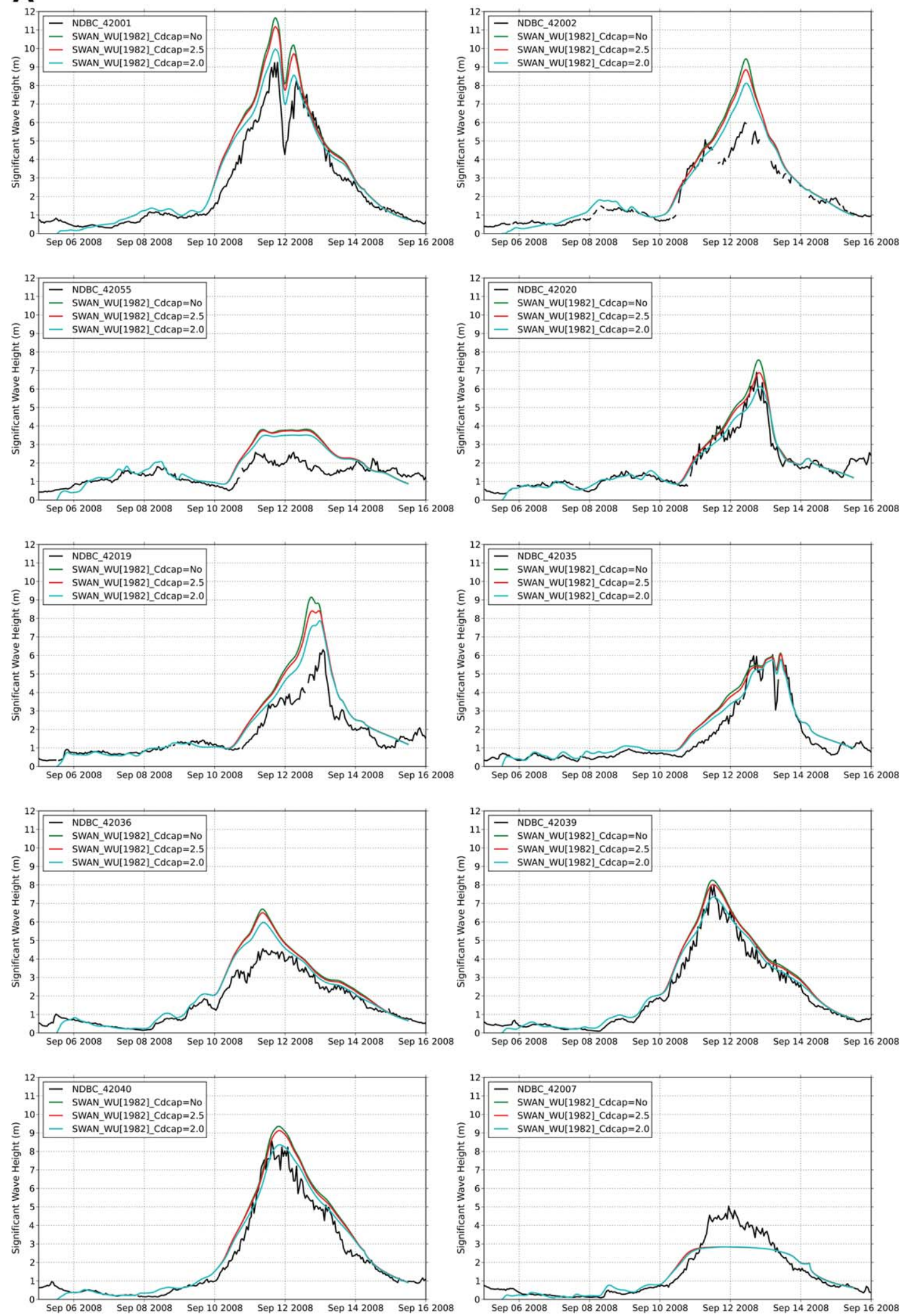

Figure 5. Time series of (a) significant wave height comparison and (b) peak period comparison among CASE01 $[W u, 1982]\left(C_{d} c a p=\right.$ "no cap"), CASE02 [Wu, 1982] $\left(C_{d} c a p=2.5\right)$, and CASE03 $[W u, 1982]\left(C_{d} c a p=2.0\right)$ against NDBC mooring buoys observed data. 
B

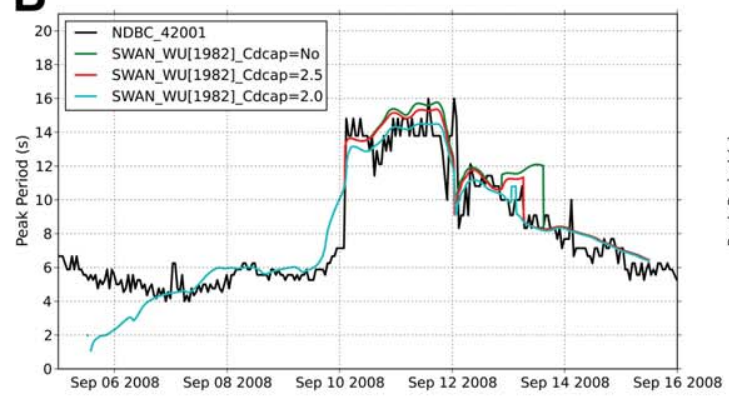

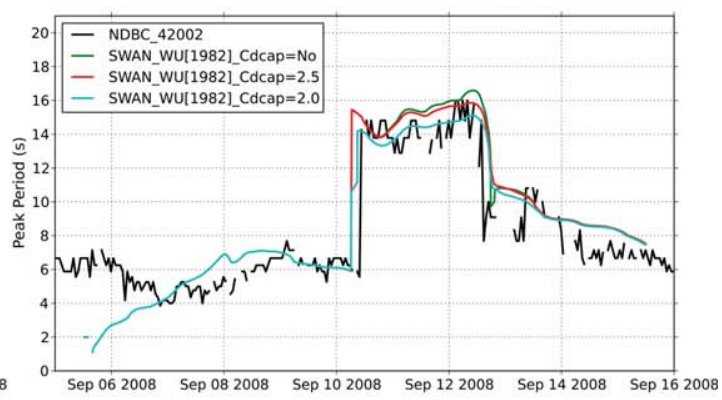

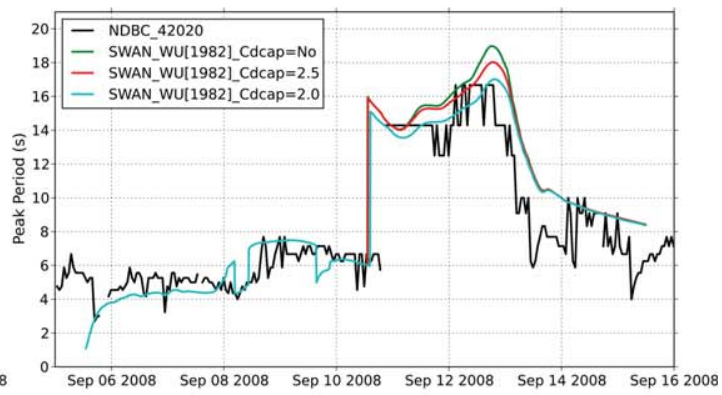

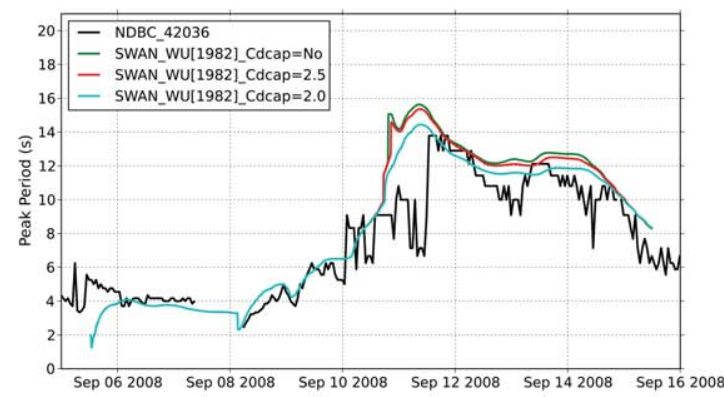
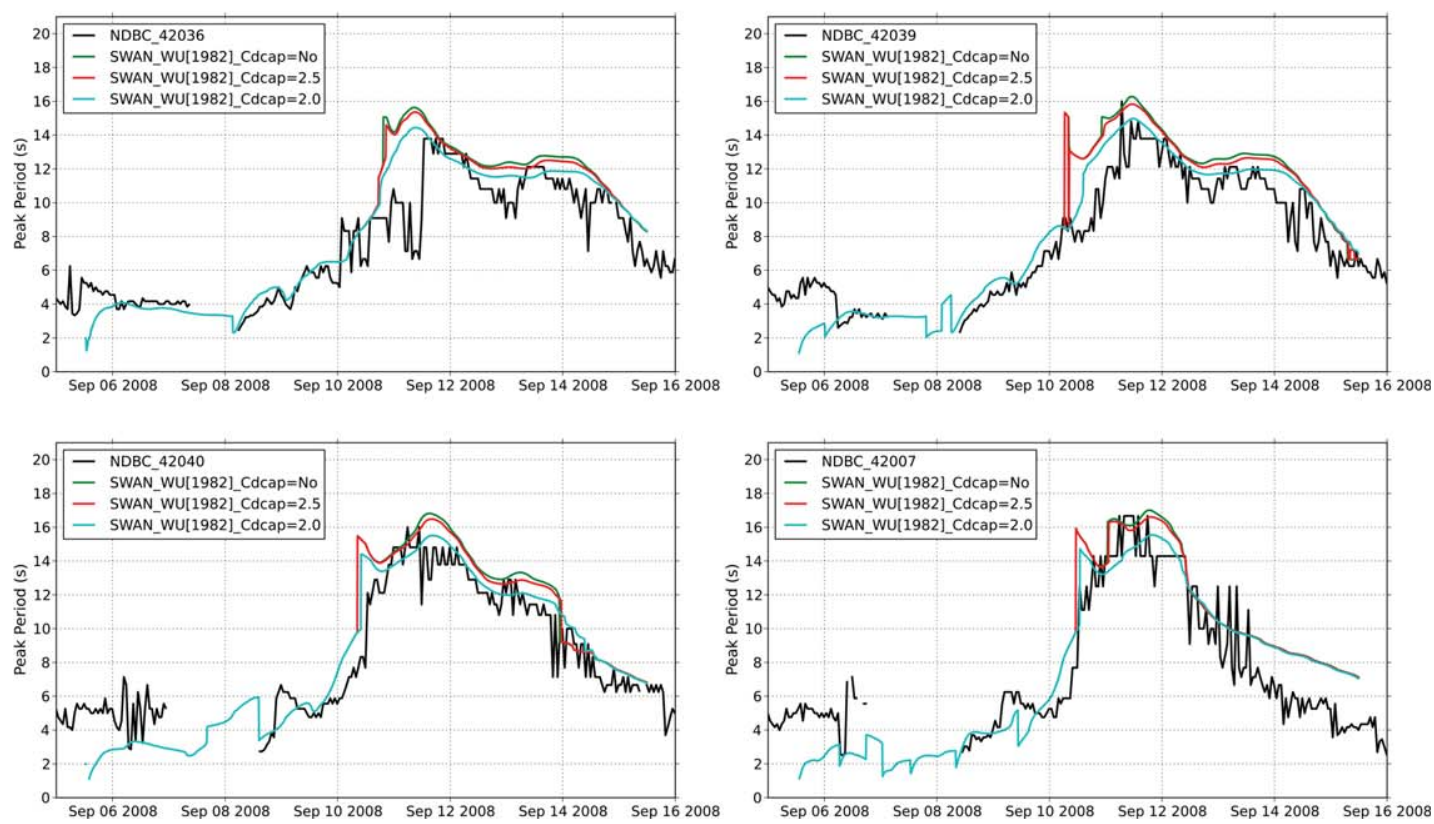

Figure 5. (continued) 

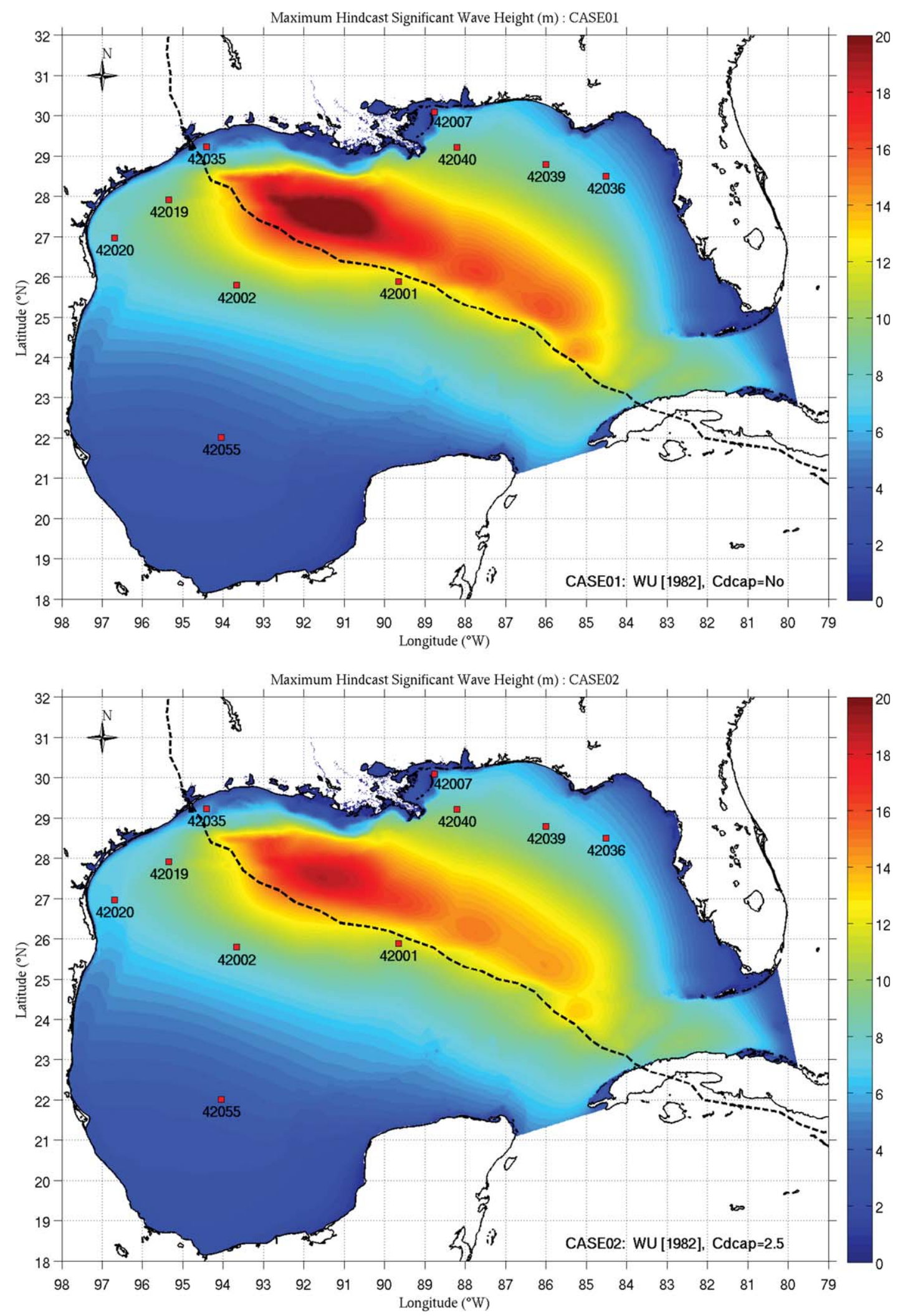

Figure 6. Maximum significant wave height distribution of (top) CASE01, (middle) CASE02, and (bottom) CASE03.

sufficient to accommodate refraction. Inclusion of refraction thus results in model instability, and hence refraction is omitted herein. An earlier work [Huang et al., 2010] with a smaller domain and higher grid resolution did include refraction with satisfactory results. The occurrence of instability with inadequate resolution is also found by Dietrich et al. [2013]. Diffraction is also omitted for reasons of resolution. 


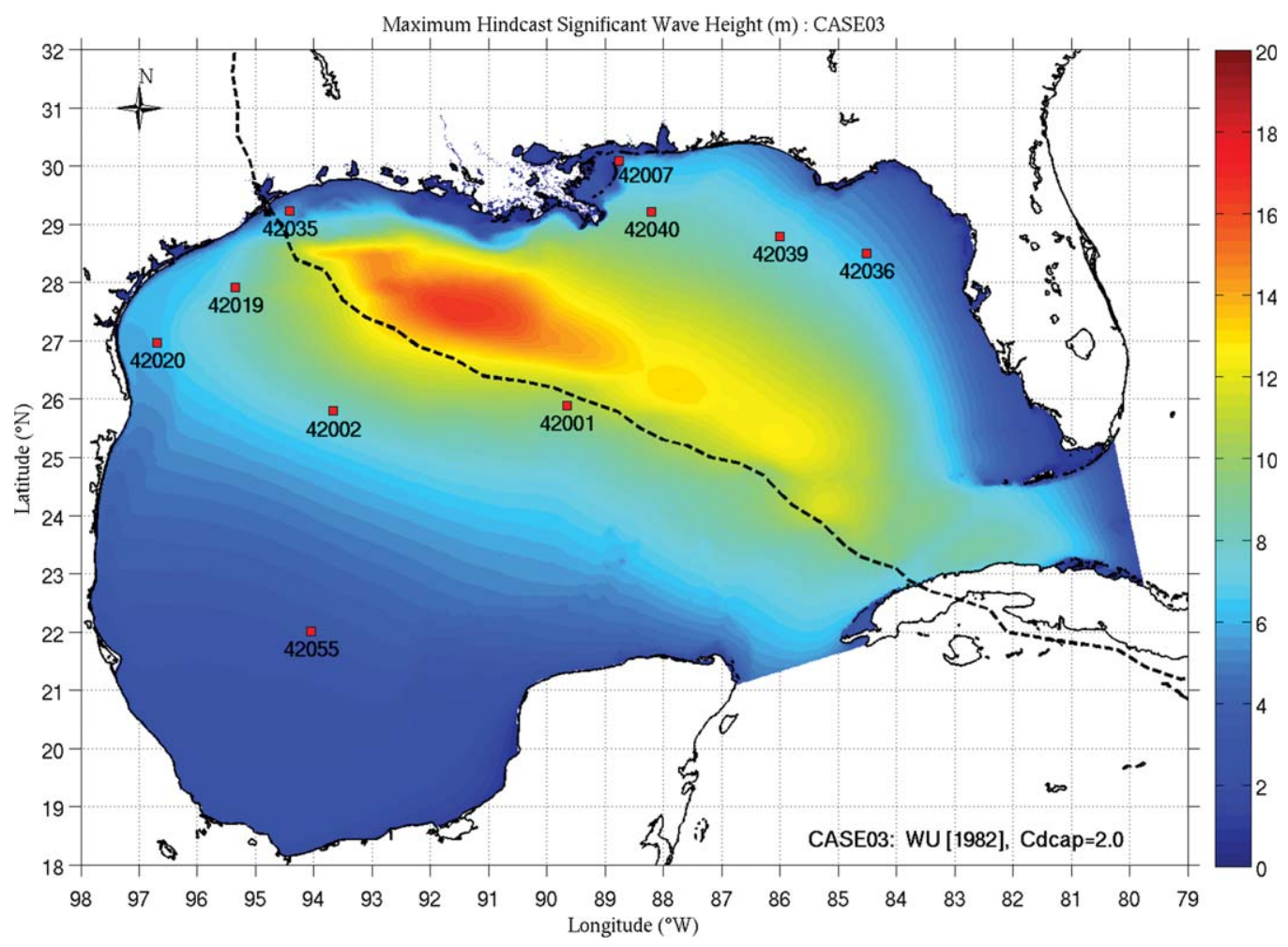

Figure 6. (continued)

[21] All of the simulations begin from a cold start and follow the evolution of Hurricane Ike through the Gulf of Mexico from UTC 12:15:00 5 September 2008 to UTC 12:00:00 15 September 2008.

\subsection{Data for Verification}

[22] Waves were observed during the Hurricane Ike passage at 10 National Data Buoy Center (NDBC) buoys moored in the Gulf of Mexico (Figure 1). Significant wave heights and peak periods from all of these will be used for comparison with the SWAN model simulations. Among them are three buoys that warrant comment. NDBC-42001 is located along the track line in deep water at the center of Gulf of Mexico. NDBC-42035 is also located along the track, but in shallow water. The forces exerted by the hurricane moved it about $0.5^{\circ}$ to the west, and its poststorm position is denoted by the black square west of its original position in Figure 1. NDBC42007 was located far from the immediate hurricane impacted area. Inaccuracies of the bathymetry data (Kerr et al., submitted manuscript, 2013) and surge effect errors [Huang et al., 2010] may have affected comparisons there.

[23] Two wave variables are used for comparison: significant wave height and peak period. The significant wave height is defined as the average of the highest one third of the wave heights observed during a certain sampling period (20 minutes on the NDBC buoys), which can also be obtained through the wave spectrum:

$$
H_{s}=4 \sqrt{\iint E(\omega, \theta) d \omega d \theta} .
$$

[24] Here $H_{\mathrm{s}}$ denotes significant wave height in meters, $E(\omega, \theta)$ is the two-dimensional variance density spectrum, $\omega$ and $\theta$ are radian frequency and direction, respectively. The peak period is defined by the peak of the wave energy spectrum, and it may be different from the peak period instantaneously observed in field.

\section{Results}

\subsection{Effects of $C_{d}$ Cap Values}

[25] Comparisons between SWAN model simulations using the $W u$ [1982] bulk formula with differing cap value constraints (CASE01, $\quad C_{d}$ cap $=$ "no cap"; CASE02, $C_{d}$ cap $=2.5$; CASE03, $C_{d}$ cap $\left.=2.0\right)$ and observations at specific NDBC buoy locations are shown for significant wave height $(\mathrm{SWH})$ and peak period in Figures $5 \mathrm{a}$ and $5 \mathrm{~b}$, respectively. All three cases capture the general evolution of the SWH very well, but large discrepancies occur for the SWH magnitudes, especially the maximum values. All three cases tend to overestimate the maximum SWH values at most of the deep water buoy locations, e.g., NDBC-42001 and NDBC-42002. The tendency is: the bigger the $C_{d}$ cap, the higher the peak value of SWH; that is, CASE01 $>$ CASE02 $>$ CASE03, although this tendency is not linear. These NDBC buoy comparisons show that the largest differences are at the deep water locations. For instance, at NDBC42001, where the depth is $3365 \mathrm{~m}$, and which lies along the Hurricane Ike track, the differences for the simulated maximum SWHs are nearly $2 \mathrm{~m}$ between CASE01 and CASE03, which exceed the observed values by about $20 \%$. For the peak periods, all three cases track the observed data well and capture the phase jump from low to high wave periods as the Hurricane Ike translates across the Gulf of Mexico. In contrast with the SWHs, the differences in peak period are not as sensitive to the $C_{d}$ cap values used. 

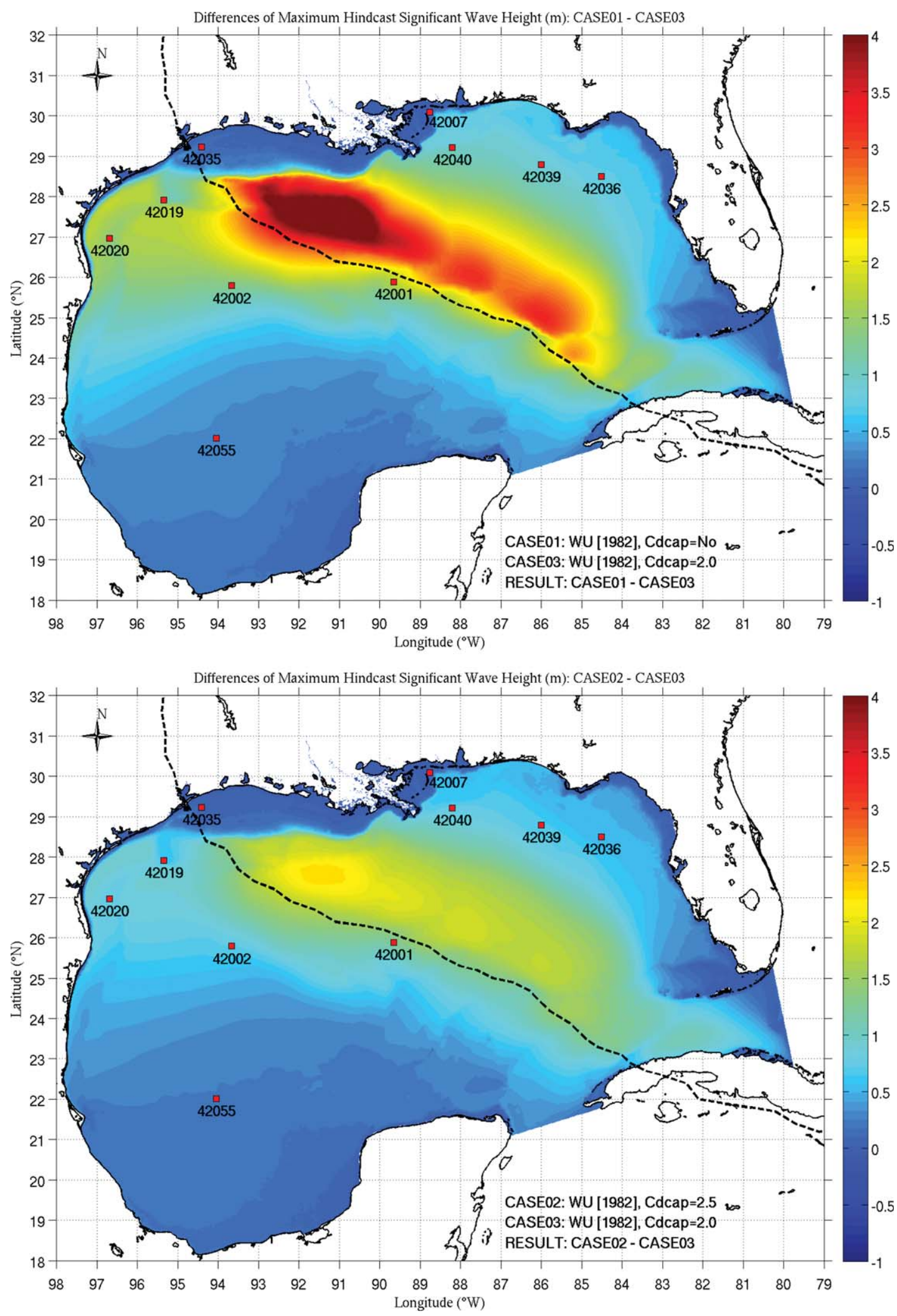

Figure 7. The differences of maximum significant wave height between (top) CASE01-CASE03 and (bottom) CASE02-CASE03.

[26] Full Gulf of Mexico perspectives on the field of maximum SWH under the three different cases relative to the NDBC buoy locations are shown in Figure 6. Similar to the maximum wind speed distribution in Figure $4 \mathrm{c}$, the maximum SWH is also distributed about the hurricane track, with the largest SWH values located on the right hand side of the 


\section{A}
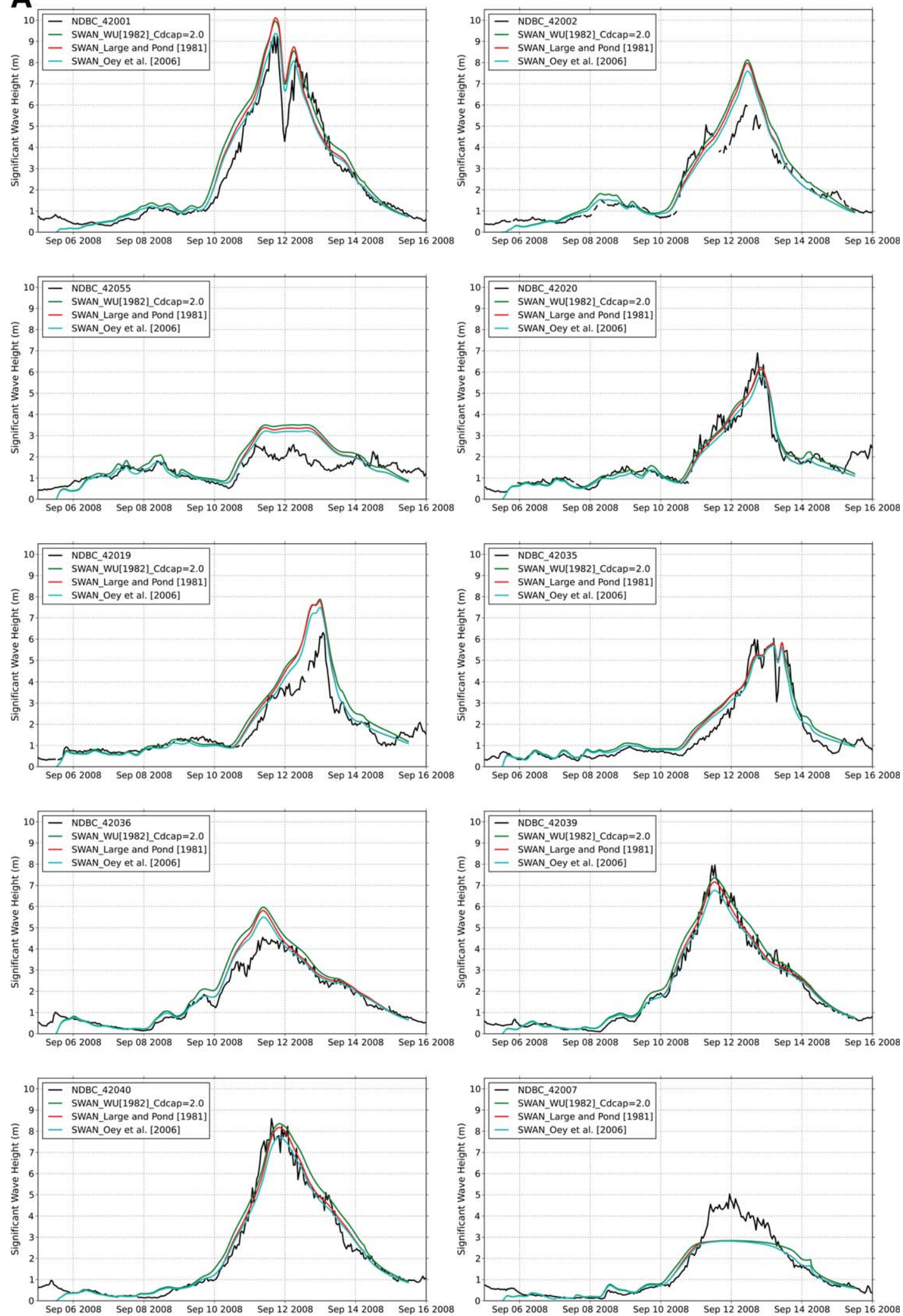

Figure 8. Time series of (a) significant wave height comparison and (b) peak period comparison among CASE03 [Wu, 1982] $\left(C_{d} c a p=2.0\right)$, CASE04 [Large and Pond, 1981] (with a cap), and CASE05 [Oey et al., 2006] against NDBC mooring buoys observed data. 
B
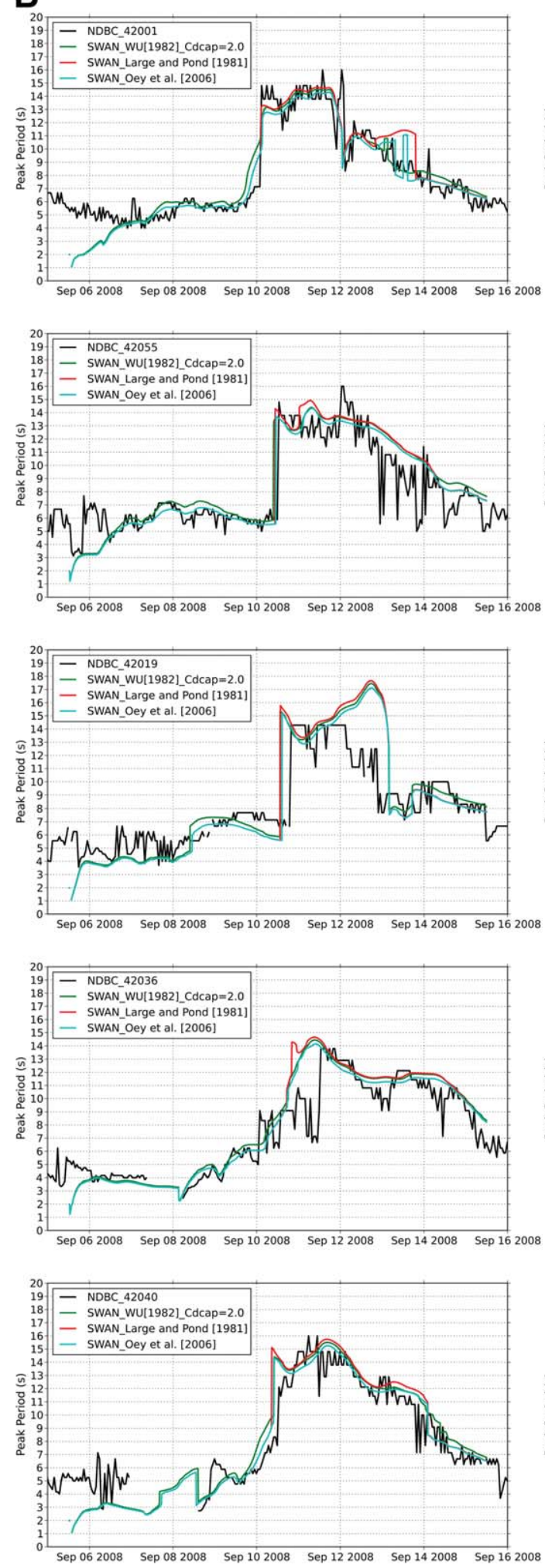
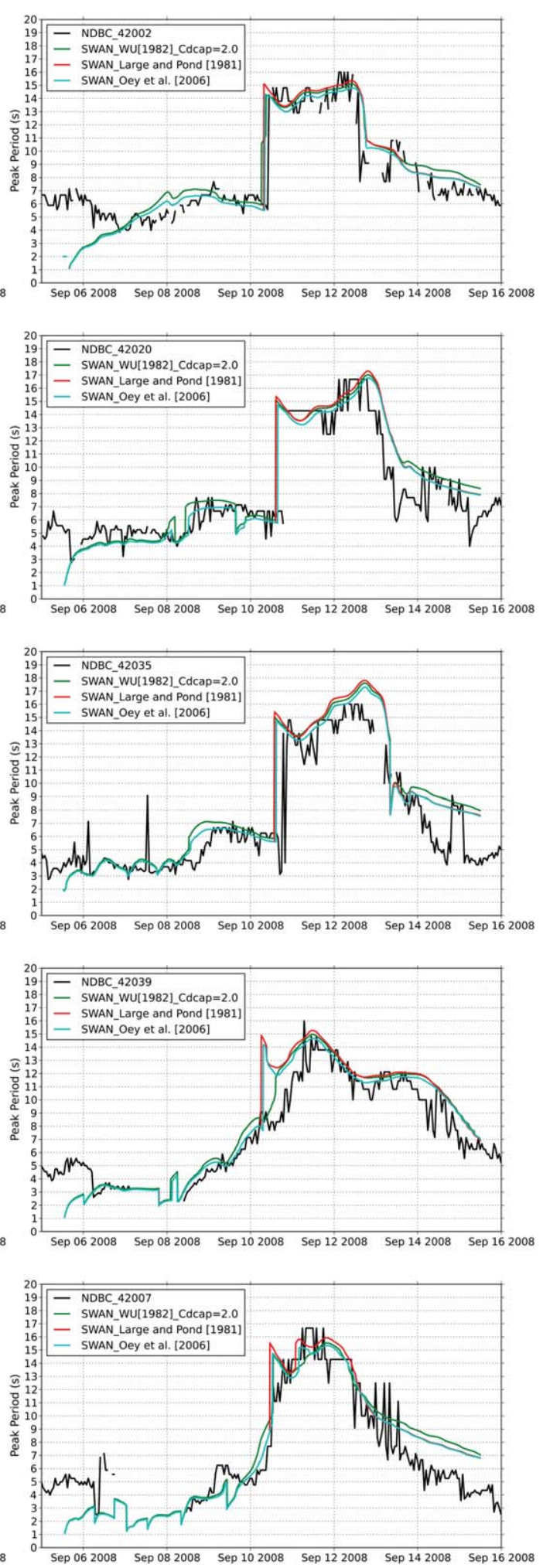

Figure 8. (continued)

advancing Hurricane Ike track line. Although the distribution patterns are very similar for all three plots, the values are quite different, with the peak SWH increasing with increasing $C_{d}$ cap.
[27] Noting that CASE03 [Wu, 1982, $\left.C_{d} c a p=2.0\right]$ agrees the best with the observations in deep water, we subjectively select CASE03 as the baseline to compare with the other two cases. Figure 7 shows that the differences 

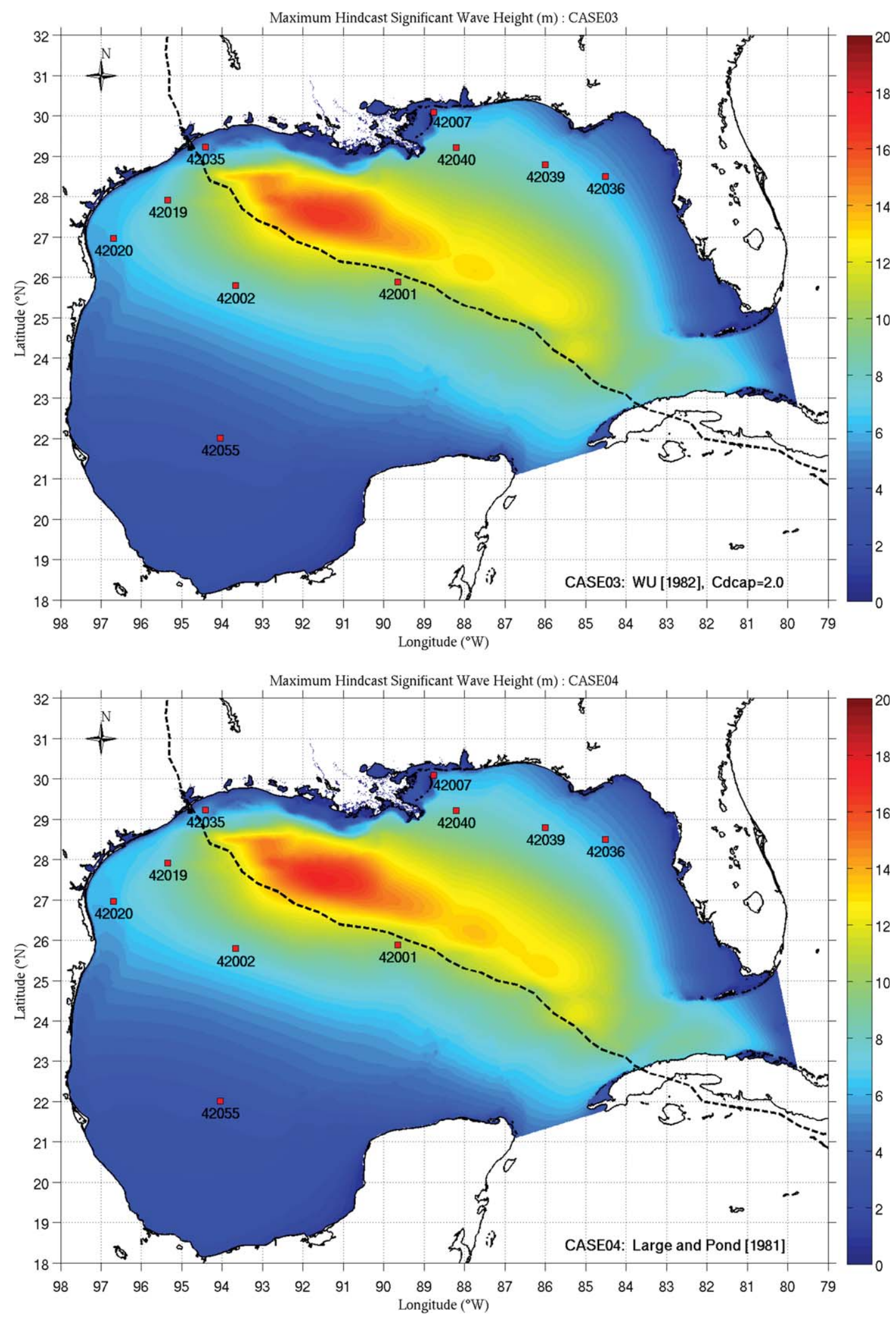

Figure 9. Maximum significant wave height distribution of (top) CASE03, (middle) CASE04, and (bottom) CASE05.

between CASE01 [Wu, 1982] ( $C_{d} c a p=$ "no cap") and CASE03 (Figure 7, top) may exceed $4 \mathrm{~m}$, or about $20 \%-$ $30 \%$ of model estimated values. For CASE02 [Wu, 1982]
$\left(C_{d} c a p=2.5\right)$, which used the SWAN manual suggested $C_{d}$ cap [SWAN Group, 2011], the difference is still about $2 \mathrm{~m}$ (Figure 7, bottom). 


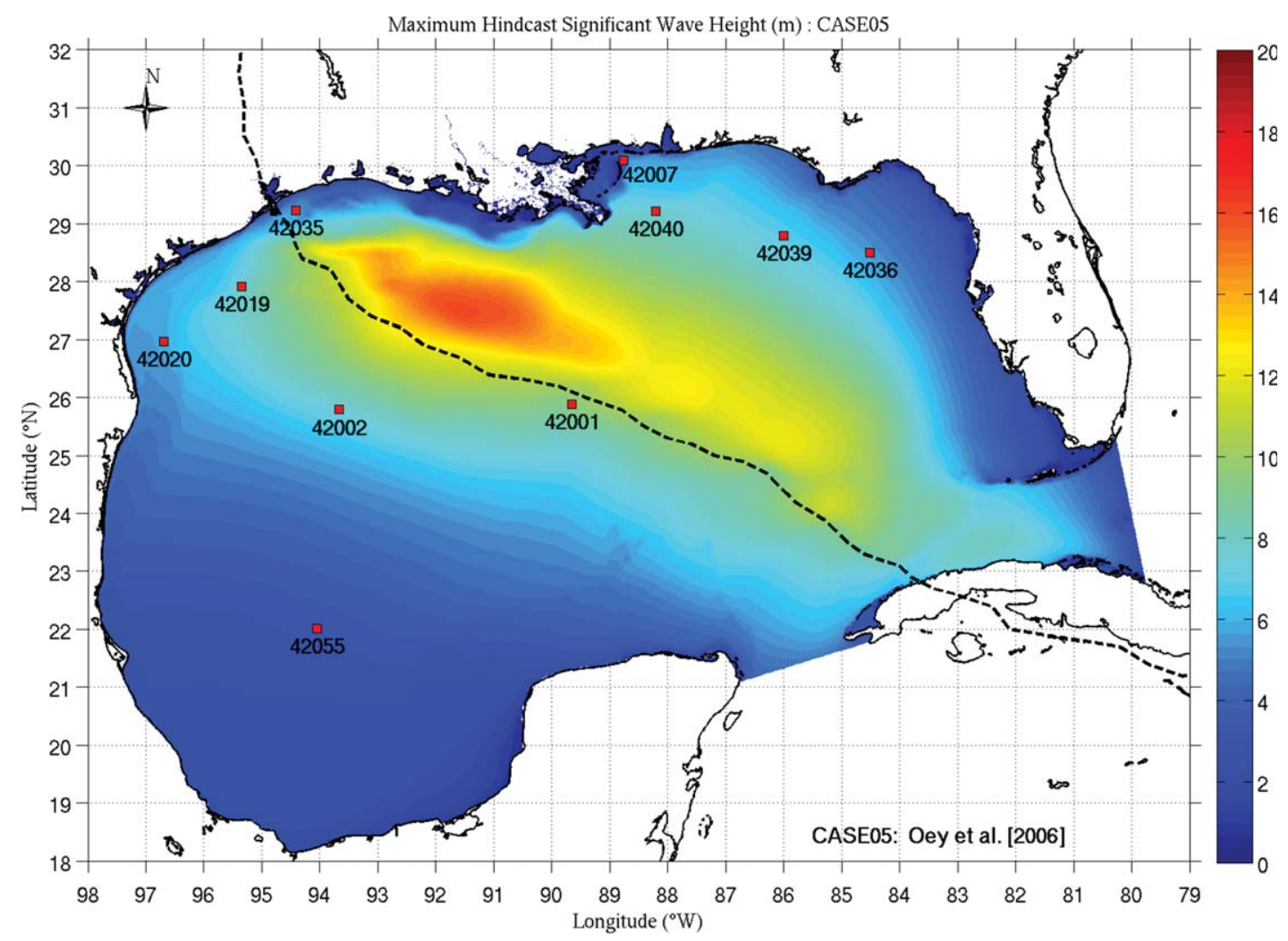

Figure 9. (continued)

[28] Notwithstanding these deep water differences, Figure 7 also shows that the discrepancies on the shelf are depth dependent. For depths less than $30 \mathrm{~m}$, the differences are relatively small and may even be ignored, regardless of how large they may be in deep water.

\subsection{Effects Due to Different Bulk Formulas}

[29] Besides the default bulk formula, model performance may be further evaluated by using alternative options. Continuing to use CASE03 [Wu, 1982] $\left(C_{d} c a p=2.0\right)$ as the baseline, Figures $8 \mathrm{a}$ and $8 \mathrm{~b}$ show the significant wave height and for peak period comparisons, respectively, for CASE04 [Large and Pond, 1981] (with a cap) and CASE05 [Oey et al., 2006] at specific NDBC buoy positions. All these three cases show similar performances for SWH. CASE05 [Oey et al., 2006] performs best at NDNC42001, but underestimates SWH at NDBC-42039 and NDBC-42020. The differences in peak period are not substantial at any of these sites.

[30] Fields of maximum SWH are illustrated in Figure 9. All three cases have very similar spatial distributions, but some small differences may be identified through the intercomparisons in Figure 10. In contrast with CASE03 [ $W u$, 1982] $\left(C_{d} c a p=2.0\right)$, CASE04 [Large and Pond, 1981] (with a cap) tends to estimate higher values on the righthand side of the Hurricane Ike track by less than $0.4 \mathrm{~m}$ and lower values on the left-hand side of hurricane track with similar magnitude (Figure 10, top). CASE05 [Oey et al., 2006] tends to estimate lower values in the deep water regions by about $0.6 \mathrm{~m}$ but keeps shallow water regions intact (Figure 10, bottom).
[31] As with the previous case comparisons, the model results in shallow water regions (less than $20 \mathrm{~m}$ to $30 \mathrm{~m}$ ) are not sensitive to different bulk formulae, as shown for CASE04 and CASE05 in Figure 10.

\section{Dynamics}

\subsection{Overestimation and Underestimation}

[32] CASE01 [Wu, 1982] ( $C_{d}$ cap = "no cap" $)$, CASE02 [Wu, 1982] $\left(C_{d} c a p=2.5\right)$, and CASE03 [Wu, 1982] $\left(C_{d}\right.$ cap $\left.=2.0\right)$ are all based on $W u$ [1982], but with different cap values, which appears to be the dominant contributor to the peak values of SWH. In Figure 2, we see that the cap values adjust the profile of bulk formula through cutoff wind speed fundamentally. For $W u$ [1982], $C_{d}$ cap $=2.5$ corresponds to a cutoff wind speed at about $26.2 \mathrm{~m} / \mathrm{s}$, while $C_{d}$ cap $=2.0$ means a cutoff wind speed at $18.5 \mathrm{~m} / \mathrm{s}$. For wind speed below the cutoff wind speed, the $U_{*}$ are calculated by the original bulk function, but for the wind speeds being limited by the cutoff value. For the passage of Hurricane Ike, Figure $4 \mathrm{c}$ shows that over $60 \%$ of the Gulf of Mexico was driven by maximum wind speeds exceeding $25 \mathrm{~m} / \mathrm{s}$. Thus, it was the capping of the bulk formulation that dominated the results of the wave height estimations for the Hurricane Ike case. For major hurricanes ( $\geq$ category 3) in the Gulf of Mexico, the spread of the wave height differences, as dependent on $C_{d} c a p$, may be even larger than for the Hurricane Ike case. The implication is that calibrations for different hurricane cases may involve different cap values, which may be practical for hindcasts 

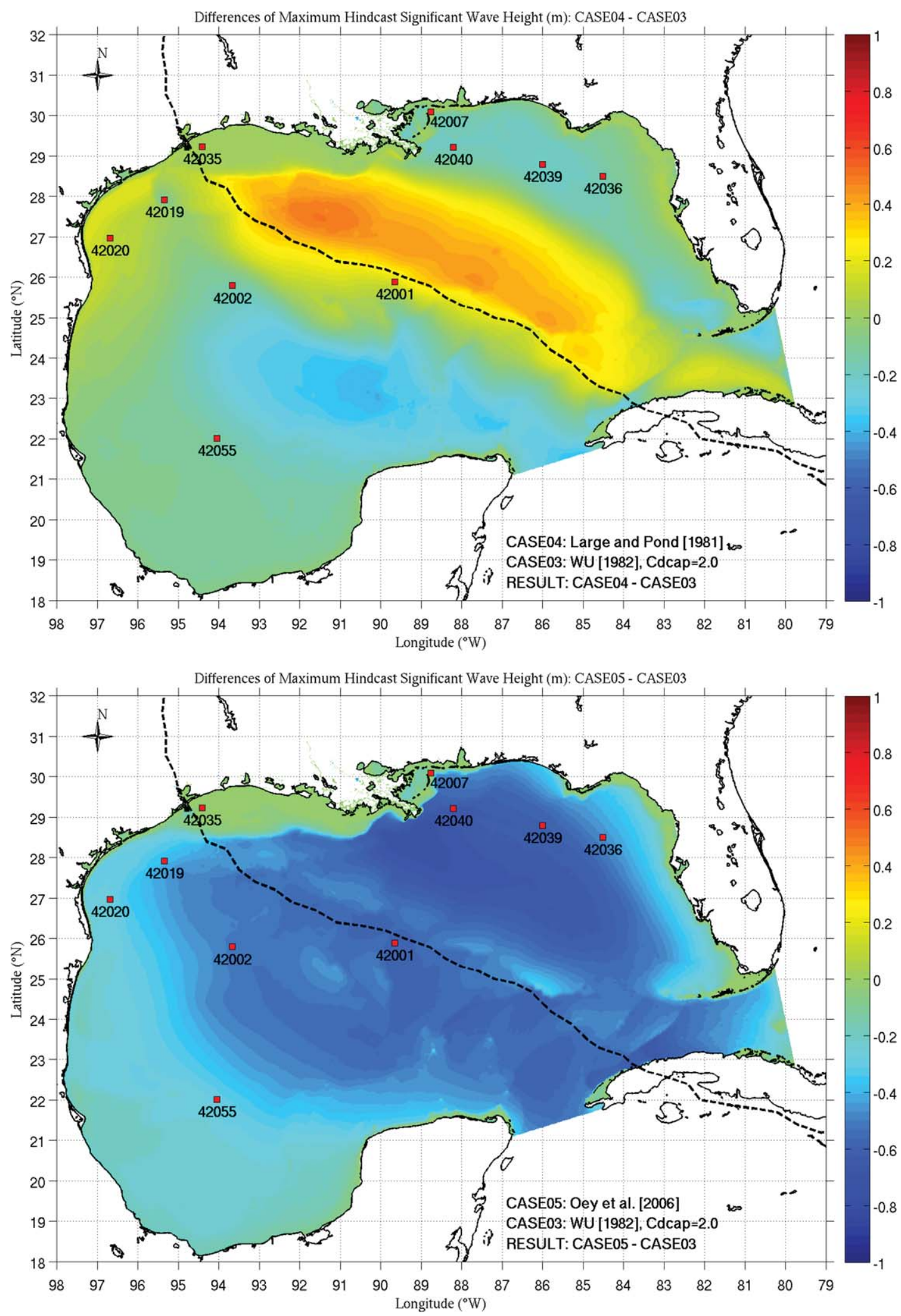

Figure 10. The differences of maximum significant wave height between (top) CASE04-CASE03 and (bottom) CASE05-CASE03.

but not for forecasts. More importantly, it represents a fundamental gap in our physical understanding of the interactions between the wind (stress) and the waves in the wave generation physics and the bulk formula as derived from observations should be independent of any numerical model. 

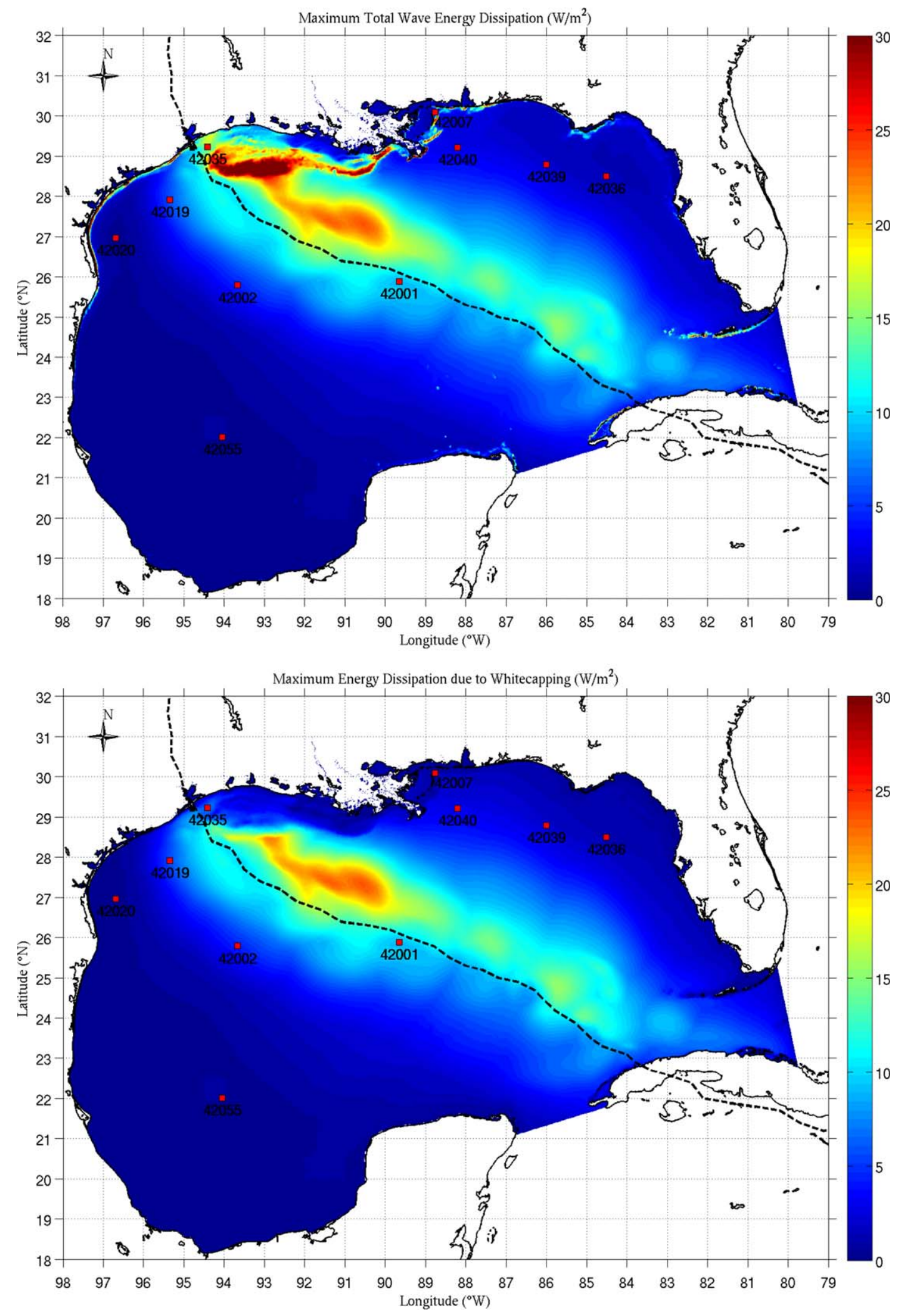

Figure 11. The (top) maximum of total wave energy dissipation, (middle) maximum energy dissipation due to whitecapping, and (bottom) surf breaking, respectively.

[33] The results show that the SWAN wave simulations benefit from the limiting of the wind drag $C_{d}$. Alternatives to our CASE03 (i.e., $W u$ [1982], $C_{d} c a p=2.0$ ) like CASE04
[Large and Pond, 1981] (with a cap) provide similar but somewhat larger SWH results because of the larger cutoff wind speed $(25 \mathrm{~m} / \mathrm{s}$ versus $18.5 \mathrm{~m} / \mathrm{s})$. Thus, the CASE04 


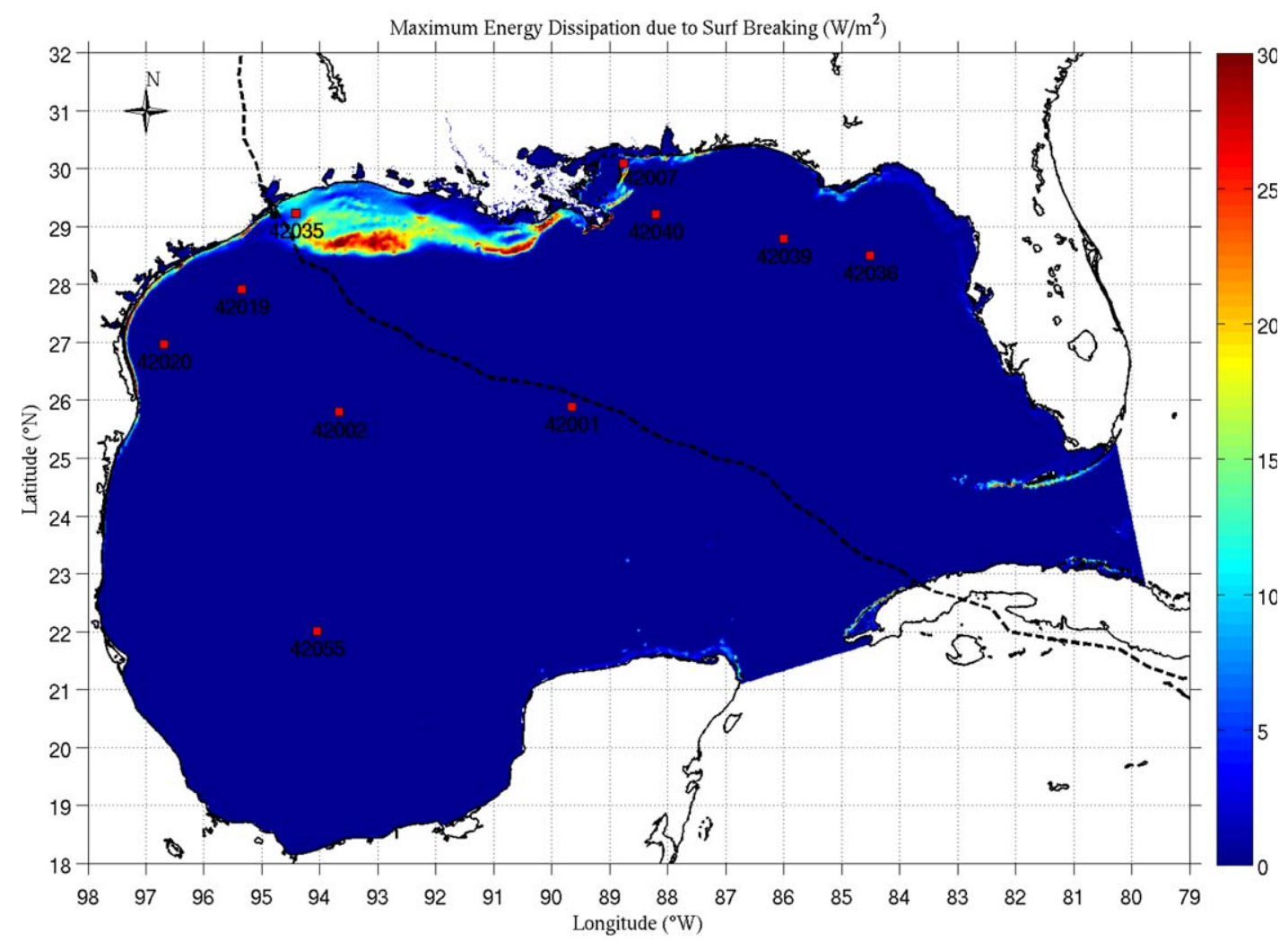

Figure 11. (continued)

SWH estimates exceeded those by CASE03 by about $0.4 \mathrm{~m}$ along the hurricane track (Figure 10, top). On the other hand, for the wind speed below the cutoff value, the $C_{d}$ profile of CASE04 is generally lower than that of CASE03 (Figure 2), providing lower estimations in regions where the wind field is of lesser magnitude.

[34] Similarly, CASE05 [Oey et al., 2006], while providing a smoother transition between moderate to high wind speeds, by having $C_{d}$ values lower than all the others (Figure 2), tends to provide smaller SWH estimates relative to the others; for instance, see the differences between CASE05 and CASE03 in the Figure 10 (bottom).

\subsection{Shallow Water Insensitivity Under Hurricane Conditions}

[35] Although SWAN is sensitive to the wind drag law in deep water, it appears to be insensitive in shallow water. Regardless of the $C_{d}$ cap value used in the same bulk formula (CASE01, CASE02, and CASE03), or even with different bulk formulae (CASE04 and CASE05), the differences found in waters shallower than $30 \mathrm{~m}$ are small. We refer this finding as "Shallow Water Insensitivity (SWI)."

[36] The SWI phenomenon must derive from wave energy dissipation due to shallow water effects. Consider CASE03 [ $W u, 1982]\left(C_{d} c a p=2.0\right)$ as an example. Figure 11 (top) shows the distribution of the maximum total wave energy dissipation during the Hurricane Ike evolution. Two prominent characters are seen. First, the pattern of the energy dissipation closely follows that of the significant wave height in the deep water (e.g., Figure 9). Second, the region of largest wave energy dissipation is located at water depths between $20 \mathrm{~m}$ and $30 \mathrm{~m}$. These two characteristics are controlled by different physics. In deep water, the only dominant mechanism that can cause wave energy dissipation is white capping, the distribution of which is shown in Figure 11 (middle). The pattern of energy dissipation by white capping appears to be in good agreement with that of the significant wave height (Figure 6, bottom). White capping, however, has a much weaker contribution for the shallower water regions beyond $20 \mathrm{~m}-30 \mathrm{~m}$. Thus, there exists a critical region, where depth-induced wave breaking tends to dominate the wave energy dissipation (e.g., Figure 11, bottom). This transition region, as evident in Figure 11, referred to as the shelf shoulder here, is where white capping transitions to depth-induced wave breaking as the principle dissipation mechanism.

\section{Discussion}

[37] Awareness of the effects of waves on storm surge originated with the Longuet-Higgins and Stewart [1964] identification of the momentum transfer from waves to the underlying currents. Regardless of the coupling mechanism adopted, parameterizations are necessary for driving either wave or circulation models. Here we note that the wind force parameterizations are usually treated separately in model systems presently used for coupling waves with surge. Using one set of parameterization for a wave model and another for a circulation model and then coupling these after individually calibrating them may be expedient for engineering applications, but may not be scientifically sound. Specifically, bulk formulations 

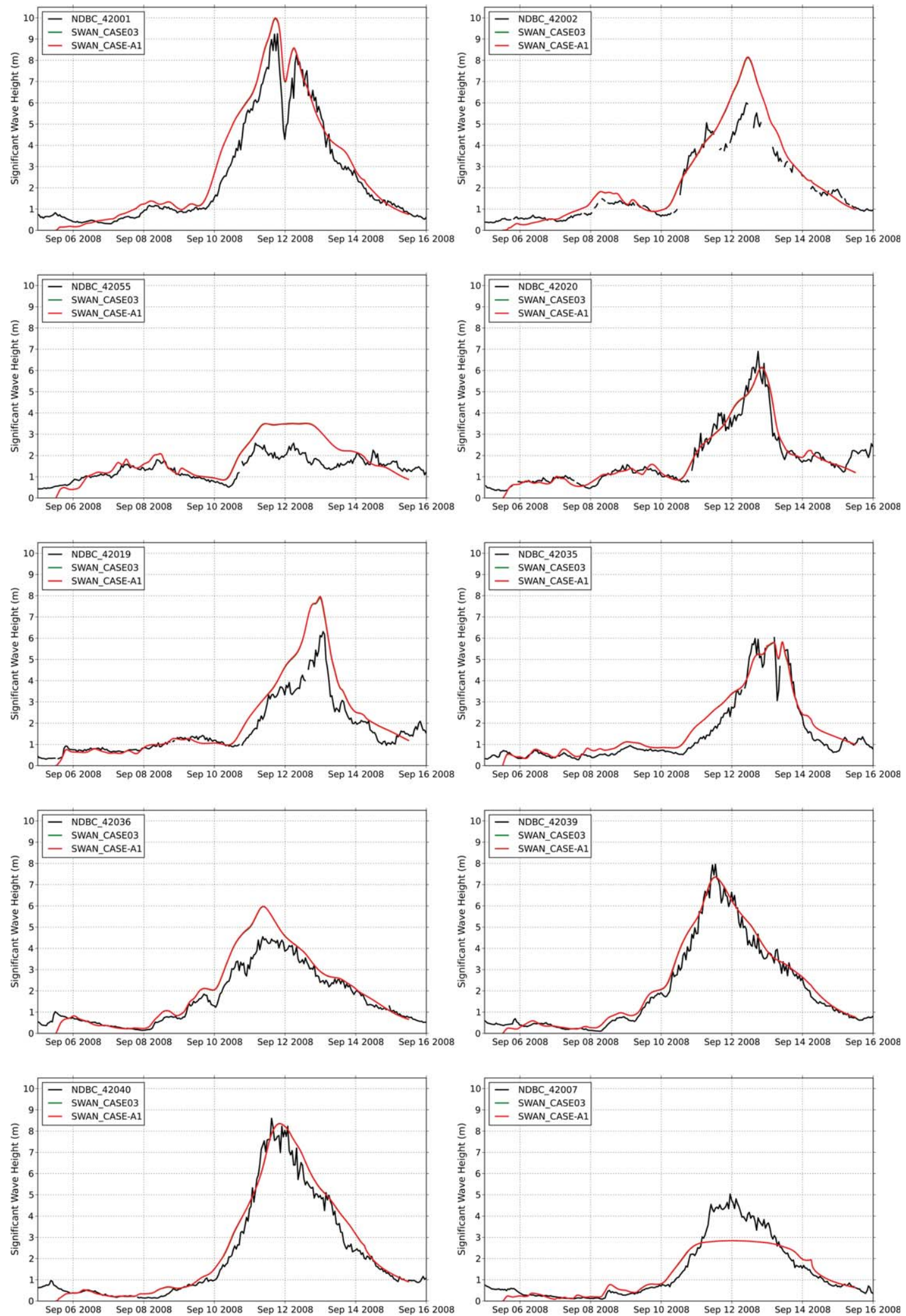

Figure A1. Significant wave height time series comparisons between the observations from NOAA NDBC moored buoys (black) and model simulations for both the baseline CASE03 (green) and the DIA sensitivity test CASE-A1 (red). 


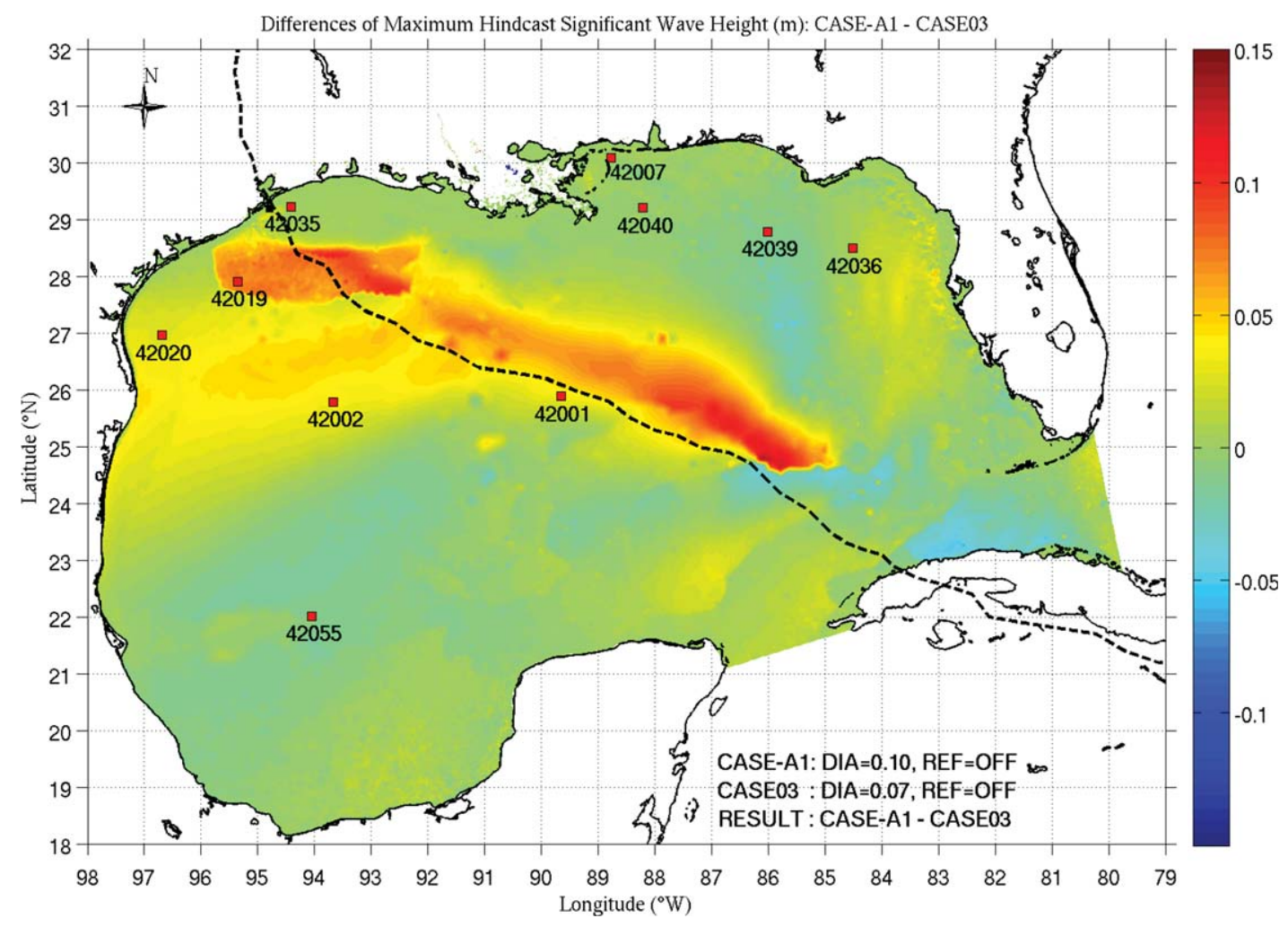

Figure A2. Maximum significant wave height differences (CASE-A1 minus CASE03) obtained over the entire model domain.

Table A1. Summary of the Sensitivity Tests

\begin{tabular}{lcccc}
\hline Case Number & Bulk Formula & $C_{d}$ cap & $\Delta \sigma / \sigma$ & Refraction \\
\hline CASE03 & $W u[1982]$ & 2.0 & 0.07 & OFF \\
CASE-A1 & $W u[1982]$ & 2.0 & 0.10 & OFF \\
\hline
\end{tabular}

derived from observations should be independent of any numerical model. An illustration of and an improvement to this problem is provided by the recently developed ADCIRC + SWAN coupled system [Dietrich et al., 2011a], which uses similar but slightly different bulk formulae to drive the SWAN and ADCIRC models. The ADCIRC model adopts the drag coefficient from Garratt [1977]:

$$
C_{d} \times 10^{3}=0.75+0.067 \times U_{10},
$$

while SWAN adopts a similar drag coefficient from $W u$ [1982]:

$$
C_{d} \times 10^{3}=0.80+0.065 \times U_{10} .
$$

[38] A $C_{d}$ cap $=3.5$ is used for both. With these parameterizations applied to Hurricanes Katrina and Rita, the coupled model overestimated the significant wave heights by about $2 \mathrm{~m}$ at the deep water (i.e., NDBC-42001 and NDBC-42002) sites subjected to hurricane wind conditions (see Dietrich et al. [2011a, Figure 11] for Hurricane Katrina and Dietrich et al. [2011a, Figure 18] for Hurri- cane Rita). A more recent work suggests the use of a smaller $C_{d}$ cap value [see Zijlema et al., 2012, Figure 3] for high wind speeds $(\geq 15 \mathrm{~m} / \mathrm{s})$. Other studies suggest that sector-based parameter values [e.g., Dietrich et al., 2011b] or wave directional spreading [e.g., Holthuijsen et al., 2012] may be necessary for hurricane simulations. These findings again highlight the dependence of either coupled or uncoupled models on their relative parameterizations.

[39] Relative to the deep water findings, the wave model sensitivity to parameter values diminishes in shallow water. Whereas the radiation stress coupling argument by Longuet Higgins and Stewart [1964] is readily appreciated for shallow water where waves break, we identified another region, termed the "shelf shoulder," where the longer wave length, deep ocean hurricanerelated waves are largely dissipated through shoalingrelated breaking before reaching the shoreline. By dissipating excess wave energy that may have been generated in deep water due to an overestimate of $U_{*}$, this "shelf shoulder" effect desensitizes the SWAN wave model results in shallow water from the parameterizations used throughout the model domain.

[40] The "shelf shoulder" effect identified herein was a consequence of the deep water SWAN application. Since SWAN was originally designed for shallow water, many SWAN applications did not include scenarios for which this effect was manifest. Thus, an overestimation of SWH under extreme weather conditions in deep water with a simultaneous lack of 
overestimation in shallow water for the same parameter values remained veiled.

\section{Summary and Conclusions}

[41] Wave simulations for Hurricane Ike, which transited the Gulf of Mexico before making landfall near Galveston, TX, were used to test model sensitivity to the wind input parameterizations, i.e., we considered the effects of the wind drag coefficient $C_{d}$ on the wave field estimations under hurricane conditions. Two principle findings are as follows.

[42] First, both the default wind input setting $\left(C_{d}\right.$ cap $=$ "no cap") $[W u, 1982]$ and the SWAN manual recommended one $\left(C_{d}\right.$ cap $\left.=2.5\right)[W u, 1982]$ overestimate the significant wave heights by Hurricane Ike in deep water. To improve the deep water performance for hurricanes, we recommend using either a smaller $C_{d}$ cap value (e.g., $C_{d} c a p=2.0$ ), or a high wind speed bulk formula [Oey et al., 2006]. Second, we found that the continental shelf region with water depths between around $20 \mathrm{~m}$ and $30 \mathrm{~m}$ ("shelf shoulder") tended to dissipate wave energy, leaving the comparisons in shallow water between simulated and observed waves insensitive to the wind drag coefficient parameterizations. Thus, SWAN model results based on the default wind input settings for hurricane cases were reliable for areas shallower than the shelf shoulder $(20-30 \mathrm{~m})$ region regardless of the tendency to overestimate $\mathrm{SWH}$ in deep waters.

\section{Appendix A : Sensitivity Tests}

[43] For the SURA-led Super-regional Model Testbed purposes, a relative frequency resolution of 0.07 (i.e., $\Delta \sigma / \sigma=0.07)$ was adopted at the request of NOAA. This differs from the SWAN default value of 0.1 (i.e., $\Delta \sigma / \sigma=0.1)$, which is the recommended value for use with the Discrete Interaction Approximation (DIA). Here we investigate the DIA sensitively to the use of a relative frequency resolution of 0.07 versus 0.1 . The baseline for the sensitivity test is CASE03, which adopts $W u$ [1982] with a $C_{d}$ cap $=2.0$, a relative frequency resolution of 0.07 (i.e., $\Delta \sigma / \sigma=0.07)$ and with refraction turned off.

[44] The concern is whether or not a deviation in relative frequency resolution translates to a loss of accuracy in the modeling of swells. Figure A1 compares significant wave height time series for the baseline CASE03 with that for CASE-A1. No discernible differences are seen amongst the 10 stations compared. Figure A2 shows a spatial map of the differences of maximum significant wave height between CASE-A1 and CASE03 for the entire simulation area. These differences are generally less than $0.1 \mathrm{~m}$.

[45] Table A1 summarizes the sensitivity test performed.

[46] Acknowledgments. This work, administered by the Southeastern Universities Research Association, was supported by NOAA via the U.S. IOOS Office (awards NA10NOS0120063 and NA11NOS0120141). Support for Huang, Weisberg and Zheng was also derived from a Florida Catastrophic Storm Risk Management Center grant administered by the Florida State University, subaward RO1270. Computations were facilitated by the Extreme Science and Engineering Discovery Environment (XSEDE) supported by NSF grant OCI-1053575.

\section{References}

Battjes, J. A. and J. P. F. M. Janssen (1978), Energy loss and set-up due to breaking of random waves, in Proceedings of the 16th International Conference on Coastal Engineering, pp. 569-587, American Society of Civil Engineering, Reston, Va.

Berg, R. (2009), Hurricane Ike Tropical Cyclone Report (AL092008), U.S Natl. Hurricane Cent., Miami, Fla. [Available at www.nhc.noaa.gov/pdf/ TCR-AL092008_Ike_3May10.pdf.]

Booij, N., R. C. Ris, and L. H. Holthuijsen (1999), A third-generation wave model for coastal regions, 1 . Model description and validation, J. Geophys. Res., 104(C4), 7649-7666.

Charnock, H. (1955), Wind stress on a water surface, Q. J. R. Meteorol. Soc., 81, 639-640.

Dietrich, J. C., M. Zijlema, J. J. Westerink, L. H. Holthuijsen, C. Dawson, R. A. Luettich Jr., R. E. Jensen, J. M. Smith, G. S. Stelling, and G. W. Stone (2011a), Modeling hurricane waves and storm surge using integrally-coupled, scalable computations, Coastal Eng., 58, 45-65, doi:10.1016/j.coastaleng.2010.08.001.

Dietrich, J. C., et al. (2011b), Hurricane Gustav (2008) Waves and Storm Surge: Hindcast, synoptic analysis and validation in Southern Louisiana, Mon. Weather Rev., 139, 2488-2522.

Dietrich, J. C., et al. (2013), Limiters for spectral propagation velocities in SWAN, Ocean Modell., doi:10.1016/j.ocemod.2012.11.005, in press.

Garratt, J. R. (1977), Review of drag coefficients over oceans and continents, Mon. Weather Rev., 105, 915-929.

Hara, T., and S. E. Belcher (2004), Wind profile and drag coefficient over mature ocean surface wave spectra, J. Phys. Oceanogr., 34, 2345-2358.

Hasselmann, K., et al. (1973), Measurements of wind-wave growth and swell decay during the Joint North Sea Wave Project (JONSWAP), Dtsch. Hydrogr. Z. Suppl., 12, A8.

Hasselmann, S., K. Hasselmann, J. H. Allender, and T. P. Barnett (1985), Computations and parameterizations of the nonlinear energy transfer in a gravity wave spectrum. Part II: Parameterizations of the nonlinear transfer for application in wave models, J. Phys. Oceanogr., 15(11), 1378-1391.

Holthuijsen, L. H., M. D. Powell, and J. D. Pietrzak (2012), Wind and waves in extreme hurricanes, J. Geophys. Res., 117, C09003, doi: 10.1029/2012JC007983.

Huang, Y., B. Yin, W. Perrie, and Y. Hou (2008), Responses of summertime extreme wave heights to local climate variations in the East China Sea, J. Geophys. Res., 113, C09031, doi:10.1029/2008JC004732.

Huang, Y., R. H. Weisberg, and L. Zheng (2010), Coupling of surge and waves for an Ivan-like hurricane impacting the Tampa Bay, Florida region, J. Geophys. Res., 115, C12009, doi:10.1029/2009JC006090.

Janssen, P. A. E. M. (1989), Wave-induced stress and the drag of air flow over sea waves, J. Phys. Oceanogr., 19, 745-754.

Jelesnianski, C. P., J. Chen, and W. A. Shaffer (1992), SLOSH: Sea, lake, and overland surges from hurricanes, NOAA Tech. Rep. NWS 48, 77 pp., Natl. Weather Serv., National Oceanic and Atmospheric Administration, Silver Spring, Md.

Komen, G. J., S. Hasselmann, and K. Hasselmann (1984), On the existence of a fully developed wind-sea spectrum, J. Phys. Oceanogr., 14, 1271-1285.

Komen, G., L. Cavaleri, M. Donelan, K. Hasselmann, S. Hasselmann, and P. A. E. M. Janssen (1994), Dynamics and Modeling of Ocean Waves, Cambridge Univ. Press, Cambridge, U. K.

Large, W. G., and S. Pond (1981), Open ocean momentum flux measurements in moderate to strong winds, J. Phys. Oceanogr., 11, 324-336.

Longuet-Higgins, M. S., and R. W. Stewart (1964), Radiation stress in water waves: A physical discussion with applications, Deep Sea Res. Oceanogr. Abstr., 11, 529-562.

Miles, J. W. (1957), On the generation of surface waves by shear flows, J. Fluid Mech., 3, 185-204.

Monin, A. S., and A. M. Obukhov (1954), Basic laws of turbulent mixing in the surface layer of the atmosphere, Tr. Akad. Nauk SSSR Geophiz. Inst., 24, 163-187.

Moon, I. J., I. Ginis, and T. Hara (2004), Effect of surface waves on air-sea momentum exchange. Part II: Behavior of drag coefficient under tropical cyclones, J. Atmos. Sci., 61, 2334-2348.

Oey, L.-Y., T. Ezer, D.-P. Wang, S.-J. Fan, and X.-Q. Yin (2006), Loop Current warming by Hurricane Wilma, Geophys. Res. Lett., 33, L08613, doi:10.1029/2006GL025873.

Phillips, O. M. (1957), On the generation of waves by turbulent wind, J. Fluid Mech., 2, 417-445.

Powell, M. D., and S. H. Houston (1996), Hurricane Andrew's landfall in South Florida Part II: Surface wind fields and potential real-time applications, Weather Forecast, 11, 329-349. 
Powell, M. D., S. H. Houston, L. R. Amat, and N. Morisseau-Leroy (1998), The HRD real-time hurricane wind analysis system, J. Wind Eng. Ind. Aerodyn., 77 and 78, 53-64.

Powell, M. D., P. J. Vickery, and T. Reinhold (2003), Reduced drag coefficient for high wind speeds in tropical cyclones, Nature, 422, 279-283.

Powell, M. D., et al. (2010), Reconstruction of Hurricane Katrina's wind fields for storm surge and wave hindcasting. Ocean Eng., 37, 26-36.

Rogers, W. E., P. A. Hwang, and D. W. Wang (2003), Investigation of wave growth and decay in the SWAN Model: Three regional-scale applications, J. Phys. Oceanogr., 33, 366-389.

Smith, S. D., et al. (1992), Sea surface wind stress and drag coefficients: The HEXOS results, Boundary Layer Meteorol., 60, 109-142.

Snyder, R. L., F. W. Dobson, J. A. Elliott, and R. B. Long (1981), Array measurement of atmospheric pressure fluctuations above surface gravity waves, J. Fluid Mech., 102, 1-59.

SWAN Group (2011), SWAN User Manual-SWAN Cycle III version 40.85, C4, P26, Delft University of Technology, Delft, Netherlands. [Available at http://www.swan.tudelft.nl.]

Tolman, H. (1991), A third-generation model for wind waves on slowly varying, unsteady and inhomogeneous depths and currents, J. Phys. Oceanogr., 21, 782-797.

WAMDI Group (1988), The WAM model-A third generation ocean wave prediction model, J. Phys. Oceanogr., 18, 1775-1810.
Wang, D.-P., and L.-Y. Oey (2008), Hindcast of waves and currents in Hurricane Katrina, Bull. Am. Meteorol. Soc., 89, 487-495.

Weisberg R. H., and L. Zheng (2008), Hurricane storm surge simulations comparing three-dimensional with two-dimensional formulations based on an Ivan-like storm over the Tampa Bay, Florida region, J. Geophys. Res., 113, C12001, doi:10.1029/2008JC005115.

Westerink, J. J., and R. A. Luettich (1991), Tide and storm surge prediction in the Gulf of Mexico using model ADCIRC-2D, Report to U. S. Army Engineers Waterways Experiment Station, 112 pp., Vicksburg, Miss., July.

Whitham, G. B. (1974), Linear and Nonlinear Waves, 363 pp., Wiley, New York.

Wu, J. (1982), Wind-stress coefficients over sea surface from breeze to hurricane, J. Geophys. Res., 87(C12), 9704-9706, doi:10.1029/ JC087iC12p09704.

Zheng, L, R. H. Weisberg, Y. Huang, R. A. Luettich, J. J. Westerink, P. C. Kerr, A. Donahue, G. Crane, and L. Akli (2013), Implications from comparisons two and three dimensional model simulations for the storm surge of Hurricane Ike, J. Geophys. Res. Oceans, doi:10.1002/ jgrc.20248, in press.

Zijlema, M. (2010), Computation of wind-wave spectra in coastal waters with SWAN on unstructured grids, Coastal Eng., 57, 267-277.

Zijlema, M., G. Ph. van Vledder, and L. H. Holthuijsen (2012), Bottom friction and wind drag for spectral wave models, Coastal Eng., 65, 19-26. 